\title{
CD56bright cells respond to stimulation until very advanced age revealing increased expression of cellular protective proteins SIRT1, HSP70 and SOD2
}

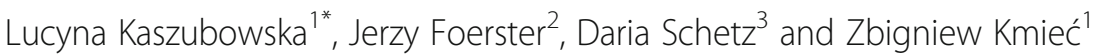

\begin{abstract}
Background: NK cells are cytotoxic lymphocytes of innate immunity composed of: cytotoxic CD56dim and immunoregulatory CD56bright cells. The study aimed to analyze the expression of cellular protective proteins: sirtuin 1 (SIRT1), heat shock protein 70 (HSP70) and manganese superoxide dismutase (SOD2) in CD56dim and CD56bright NK cells of the young, seniors aged under 85 ('the old') and seniors aged over 85 ('the oldest'). We studied both non-stimulated NK cells and cells stimulated by IL-2, LPS or PMA with ionomycin. The expression level of proinflammatory cytokines TNF and IFN- $\gamma$ was also assessed in NK cell subsets and some relationships between the studied parameters were analyzed.
\end{abstract}

Results: CD56bright cells showed sensitivity to most of the applied stimulatory agents until very advanced age in regards to the expression of SIRT1 and intracellular HSP70. On the contrary, CD56dim cells, sensitive to stimulation by most of the stimulatory agents in the young and the old, in the oldest lost this sensitivity and presented rather high, constant expression of SIRT1 and HSP70, resistant to further stimulation. With reference to SOD2 expression, CD56dim cells were insensitive to stimulation in the young, but their sensitivity increased with ageing. CD56bright cells were sensitive to most of the applied agents in the young and the old but in the oldest they responded to all of the stimulatory agents used in the study. Similarly, both NK cell subsets were sensitive to stimulation until very advanced age in regards to the expression of TNF and IFN- $\gamma$.

Conclusions: CD56bright cells maintained sensitivity to stimulation until very advanced age presenting also an increased expression of SIRT1 and HSP70. CD56dim cells showed a constantly increased expression of these cellular protective proteins in the oldest, insensitive for further stimulation. The oldest, however, did not reveal an increased level of SOD2 expression, but it was significantly elevated in both NK cell subsets after stimulation. The pattern of expression of the studied cellular protective proteins in ageing process revealed the adaptation of NK cells to stress response in the oldest seniors which might accompany the immunosenescence and contribute to the long lifespan of this group of the elderly.

Keywords: NK cells, CD56dim cells, CD56bright cells, Ageing, SIRT1, HSP70, SOD2, Innate immunity, Immunosenescence, Cellular protective proteins

\footnotetext{
*Correspondence: Ikras@gumed.edu.pl

'Department of Histology, Medical University of Gdańsk, Dębinki 1, 80-211

Gdańsk, Poland

Full list of author information is available at the end of the article
}

(c) The Author(s). 2018 Open Access This article is distributed under the terms of the Creative Commons Attribution 4.0 International License (http://creativecommons.org/licenses/by/4.0/), which permits unrestricted use, distribution, and reproduction in any medium, provided you give appropriate credit to the original author(s) and the source, provide a link to the Creative Commons license, and indicate if changes were made. The Creative Commons Public Domain Dedication waiver (http://creativecommons.org/publicdomain/zero/1.0/) applies to the data made available in this article, unless otherwise stated. 


\section{Background}

Natural killer cells (NK cells) are innate lymphoid cells (ILCs) crucial for immune response against viral infection and tumor cells [1]. They are characterized by the expression of CD56 surface marker and divided into two functionally different subsets based on their cell surface density of CD56. CD56bright cells, less numerous subset (10\% of peripheral blood NK cells) are the primary source of NK cell-derived immunoregulatory cytokines, whereas CD56dim cells that constitute the majority of peripheral blood NK cell population (90\%) are highly cytotoxic effector cells that can also produce high levels of IFN- $\gamma$ upon stimulation [2, 3]. Our group [4] and other investigators showed that the absolute number of NK cells increases with age similarly to the ratio of CD3-CD56 ${ }^{\mathrm{dim}}$ to CD3-CD56 ${ }^{\text {bright }}$ cells [5-7]. These changes result from the increase of the absolute number of CD56dim NK cells and decline of the total number of CD56 $6^{\text {bright }}$ cells within peripheral blood in the process of ageing $[4,5,7,8]$. However, detailed characteristics of the alterations of the CD56bright and CD56dim cells in ageing process have not yet been described.

NK cells are classified as part of the innate immune system due to expression of germ-line encoded receptors that do not undergo receptor gene rearrangement to generate antigen-specific receptors like $\mathrm{T}$ and $\mathrm{B}$ lymphocytes [9]. NK cells can exhibit some features usually associated with adaptive immunity, i.e. they can adapt to changing cellular environment and develop a type of antigen-specific immunological memory [10, 11]. After stimulation by cytokines, e.g. IL-2, IL-12, IL-15 and IL-18 or a target cell challenge they produce a range of cytokines (TNF, IFN- $\gamma$, IL-5, IL-10, IL-13, GM-CSF) and chemokines (IL-8, MIP-1 $\alpha$, MIP-1 $\beta$ and RANTES [12-14].

Interleukin 2 is crucial for NK cells' growth, proliferation and enhancement of their cytolytic function. It activates JAK/STAT pathway and transcription of various genes involved in the regulation of these processes $[15,16]$. IL-2 can activate also PI3K-Akt or MEK/ERK pathway resulting in cell survival and cell cycle progression [17]. MEK/ ERK pathway was also shown to be necessary for the activation of NK cells, IFN- $\gamma$ secretion, CD25 and CD69 expression, and enhanced cytotoxic function [18].

Lipopolysaccharide (LPS) is a component of the outer membrane of Gram-negative bacteria recognized by Toll-like receptors 4 (TLR4) [19-21]. These receptors play a pivotal role in innate immunity and are expressed also on the surface of NK cells [22]. TLR4 receptors were also reported to be expressed intracellularly in NK cells of healthy humans [23]. TLR4 binds lipid A, a part of lipopolysaccharide molecule and this interaction activates NF- $\mathrm{kB}$ pathway and expression of genes coding for proinflammatory cytokines, e.g. TNF, IL-1, IL-6, GM-CSF and chemokines, e.g. IL-8, RANTES, MIP-1 $\alpha$,
MCP-1 [24, 25]. Kanevskiy et al. suggests also the existence of a distinct, TLR4-independent mechanism of a direct action of LPS on NK cells, that leads to their activation and secretion of IFN- $\gamma[26]$.

Phorbol 12-myristate 13-acetate (PMA) is a protein kinase $\mathrm{C}$ (PKC) activator used for a strong and unspecific stimulation of NK cells in combination with ionomycin $\left(\mathrm{Ca}^{2+}\right.$ ionophore A23187), a calcium ion channel-opening antibiotic. PMA mimicks the action of inositol triphosphate (IP3) and increases intracellular cytoplasmic free $\mathrm{Ca}^{2+}$ concentration by causing an influx of calcium ions from the extracellular space into the cell [27]. $\mathrm{Ca}^{2+}$-PKC pathway is involved in the phosphorylation of STAT4 which binds to promoters of numerous genes, including proinflammatory cytokines, e.g. IFN- $\gamma$ and TNF. PMA with ionomycin are usually used for short (1-6 h) cell stimulations to induce the expression of cytokines, e.g. IFN- $\gamma$ [28-30]. However, the combination of these agents is also applied for both short [30] and longer (up to $48 \mathrm{~h}$ ) cell stimulations to analyze profiles of gene and protein expression [31, 32].

Ageing of the immune system is associated with continuing increase in the proinflammatory status caused by the declining capacity to cope with stress factors and deterioration of regulatory mechanisms concerning cytokine secretion. This process is characterized by increased serum levels of proinflammatory cytokines IL-6 and TNF, raised level of $C$ reactive protein, decreased concentration of anti-inflammatory cytokine IL-10 [33] and is described as inflamm-aging [34]. Immunosenescence is also accompanied by the increase in oxidative stress caused by disparity between the level of reactive oxygen species (ROS) generation and diminished activity of cellular anti-oxidative mechanisms [35-37].

Adaptive stress response protects cells against unfavorable environmental conditions and different types of injuries. Eukaryotic cells evolved networks of signaling pathways to detect and control diverse forms of stress. Among them, chaperons play a key role. They are highly conserved proteins, responsible for preservation of the correct conformation of cellular macromolecules, i.e. proteins, RNA and DNA [38]. Their expression was found to highly correlate with maximum lifespan of vertebrates, indicating higher levels of HSP expression in longer-lived species of mammals and birds [39]. HSP70 play then a pivotal role in the protein quality control system, which is of vital importance to counteracting the ageing process [36].

SIRT1 is a redox-sensitive protein that reveals protective properties mediating an oxidative stress response [40]. It directly deacetylates several transcription factors involved in the regulation of expression of some antioxidant and cellular protective genes, e.g. the FOXO family of transcription factors which promote the expression of stress response genes including SOD2 [41, 42]. SIRT1 promotes 
mitochondrial biogenesis and upregulates the expression of genes involved in oxidative stress response, i.e. glutathione peroxidase (GPx1), catalase, superoxide dismutases 1 and 2 (SOD1 and SOD2) [43, 44]. Westerheide et al. showed also that in mammalian cells SIRT1 is involved in the regulation of heat shock response as it directly deacetylates HSF1 [45]. Heat shock factor 1 (HSF1) is activated in response to a variety of stresses - including heat shock, hypoxia, misfolded proteins, free radicals and adenosine triphosphate depletion. These two systems of cellular protective proteins function together to protect cells from various stresses, promote survival and extend the lifespan of invertebrates, e.g. Caenorhabditis elegans and Drosophila melanogaster [40,46] or small mammals as was shown in experiments on mouse embryonic fibroblasts derived from SIRT1 knockout mice [41].

Recently, the expression of SIRT1, HSP70 and SOD2 in the elderly, including seniors in very advanced age, has been described also in NK cells [4, 47]. However, there are no data about the expression of cellular protective proteins in two subpopulations of NK cells, i.e. CD56dim and CD56bright cells during ageing. Therefore, the aim of our study was to analyze the expression of SIRT1, HSP70 and SOD2 in CD56dim and CD56bright NK cells of the young, seniors under 85 and the oldest seniors aged over 85. The studied cells were non-stimulated or stimulated by IL-2, LPS or PMA with ionomycin to assess the expression level of the analyzed protective proteins. Moreover, the expression of proinflammatory cytokines, i.e. TNF and IFN- $\gamma$ was also evaluated in the studied NK cell subpopulations in various age groups. Finally, we analyzed the potential relationships between the studied proteins in the process of ageing.

\section{Material and methods \\ Participants}

Eighty six volunteers aged between 19 and 94 years (62 women and 24 men) participated in this study. The exclusion criteria included: CRP $>5 \mathrm{mg} / \mathrm{L}$, cancer, autoimmune disease, diabetes, infection, use of immunosuppressors, glucocorticoids or non-steroid anti-inflammatory drugs (NSAID). Absence of dementia was assessed using the "Mini Mental State Examination" and only seniors with the score above 23 points were qualified to the study [48]. Senior volunteers underwent then a geriatric assessment. The Katz's index of independence in "Activities of Daily Living" (ADL) was used and only seniors with 5-6 points were enrolled to the study [49]. Senior volunteers were recruited among inhabitants of local retirement homes whereas young volunteers were students of Medical University of Gdańsk, Poland. The participants were subdivided into 3 groups including: 31 young subjects referred to as 'young' (20.9 \pm 0.3 years, range $19-24$ years, 22 women and 9 men); 30 seniors aged under 85 referred to as 'old' (mean age $75.6 \pm 0.9$ years, range $65-84$ years, 20 women and 10 men) and 25 seniors at the age over 85 referred to as the 'oldest' (mean age $88.4 \pm 0.5$ years, range 85-94 years; 20 women and 5 men). All volunteers signed informed consent and the study received approval from Ethical Committee of Medical University of Gdańsk, Poland (No 225/2010). An immunological characteristics of the study population was described earlier [4].

Preparation of peripheral blood mononuclear cell cultures Peripheral blood mononuclear cells (PBMCs) were isolated from venous blood samples collected in tubes with EDTA by conventional ficoll-uropoline density gradient centrifugation. PBMCs were then washed and resuspended in RPMI1640 medium supplemented with $5 \%$ FBS, penicillin $(100 \mathrm{U} / \mathrm{ml})$ - streptomycin $(100 \mu \mathrm{g} / \mathrm{ml})$ and 2-mercaptoethanol $\left(5 \times 10^{-5} \mathrm{M}\right)$ (all purchased from SigmaAldrich, Saint Louis, MO, USA). Cells $\left(5 \times 10^{5} /\right.$ $0.5 \mathrm{ml}$ ) were cultured for $48 \mathrm{~h}$ in the absence (control) or presence of IL-2 (100 U/ml) (BD Biosciences, San Jose, CA, USA), LPS $(1 \mu \mathrm{g} / \mathrm{ml})$ or PMA $(50 \mathrm{ng} / \mathrm{ml})$ and ionomycin $(500 \mathrm{ng} / \mathrm{ml}$, all purchased from Sigma-Aldrich). PBMCs treated in this way were analyzed for the expression of SIRT1, SOD2 and HSP70 (surface and intracellular). The intracellular expression of TNF and IFN- $\gamma$, was studied in PBMCs $\left(5 \times 10^{5} / 0.5 \mathrm{ml}\right)$ cultured in the absence (control) or presence of IL-2 (100 U/ml) (BD Biosciences, San Jose, CA, USA), LPS (1 $\mu \mathrm{g} / \mathrm{ml})$ Sigma-Aldrich, Saint Louis, MO, USA) or PMA (50 ng/ml) and ionomycin $(500 \mathrm{ng} / \mathrm{ml}$ ) (SigmaAldrich, Saint Louis, MO, USA) for $5 \mathrm{~h}$. Simultaneously, Golgi Stop reagent $(0.5 \mu \mathrm{l} /$ well in $0.5 \mathrm{ml}$ of medium, BD Biosciences, San Jose, CA, USA) was added to PBMC cultures $\left(5 \times 10^{5}\right.$ / $0.5 \mathrm{ml})$ to stop extracellular export of cytokines. Then PBMCs were collected and washed with $1 \mathrm{ml}$ of $\mathrm{BD}$ Staining Buffer.

\section{Staining of surface and intracellular antigens for flow cytometry}

PBMCs $\left(2.5 \times 10^{5}\right.$ cells $)$ were aliquoted into flow cytometry tubes and CD3-FITC-conjugated $(0.125 \mu \mathrm{g} / \mathrm{ml}$; clone UCHT1) (BD Biosciences, San Jose, CA, USA) or CD3-PE-Cy7-conjugated $(0.125 \mu \mathrm{g} / \mathrm{ml}$; clone SK7) (BD Biosciences, San Jose, CA, USA), CD56-APC-conjugated $(0.6 \mu \mathrm{g} / \mathrm{ml}$; clone NCAM16.2) (BD Biosciences, San Jose, CA, USA) and Hsp70-PE-conjugated (1 $\mu \mathrm{g} / \mathrm{ml}$; clone N27F34) (Abcam, Cambridge, England) monoclonal antibodies were added for cell surface antigen staining. After $30 \mathrm{~min}$ of incubation in the dark at room temperature cells were washed twice with $1 \mathrm{ml}$ of BD Staining Buffer (PBS without $\mathrm{Ca}^{2+}$ and $\mathrm{Mg}^{2+}, 1 \% \mathrm{FBS}, 0.09 \%$ sodium azide) and resuspended in $0.25 \mathrm{ml}$ of Fixation/ Permeabilization Solution for $20 \mathrm{~min}$ at $4{ }^{\circ} \mathrm{C}$ following manufacturer's protocol (BD Cytofix/Cytoperm Fixation/ 
Permeabilization Kit). Cells were washed twice with $1 \mathrm{ml}$ of BD Perm/Wash buffer and relevant volumes of MnSOD-FITC-conjugated (1 $\mu \mathrm{g} / \mathrm{ml}$; clone $\mathrm{MnS}-1$ ) (eBioscience, San Diego, CA, USA), Hsp70-PE-conjugated (1 $\mu \mathrm{g} / \mathrm{ml}$; clone N27F34) (Abcam, Cambridge, England), SIRT1-Alexa Fluor 488 - conjugated $(1 \mu \mathrm{g} / \mathrm{ml}$; clone 19A7AB4) (Abcam, Cambridge, England), TNF-PE-Cy7conjugated $(0.125 \mu \mathrm{g} / \mathrm{ml}$; clone MAb11) (BD Biosciences, San Jose, CA, USA) or IFN- $\gamma$-PE-conjugated $(0.125 \mu \mathrm{g} / \mathrm{ml}$; clone 4S.B3) (BD Biosciences, San Jose, CA, USA) monoclonal antibodies were added for staining of intracellular antigens following the manufacturer's instructions. After $30 \mathrm{~min}$ of incubation in the dark at room temperature cells were washed twice with $1 \mathrm{ml}$ of BD Perm/Wash buffer and resuspended in Staining Buffer prior to flow cytometric analysis. Samples were run on a BD FACSCalibur flow cytometer equipped with argon-ion laser $(488 \mathrm{~nm})$ and data were evaluated with BD CellQuest Pro software (BD Biosciences, San Jose, CA, USA) after collecting 10,000 gated events (lymphocytes). Peripheral blood lymphocytes were gated using forward (FSC) and side scatter (SSC) parameters. NK cells were identified in the CD3-negative region based on the expression of CD56 surface marker and defined as CD3-CD56+ cells. NK cell subsets were then discriminated, i.e. CD56dim and CD56bright cells and further analyzed for the frequency of cells expressing the particular cellular protective protein (SIRT1, HSP70, SOD2) or cytokine (TNF and IFN- $\gamma)$. Relevant isotype controls for both surface and intracellular staining were also used. Results were then presented in two ways, i.e. as percentages of CD56dim and CD56bright cells with the expression of the studied protein (\% of positive cells) and mean fluorescence intensity (MFI).

\section{Statistics}

All data are expressed as means \pm SEM. Normality of data distribution was analyzed by Shapiro-Wilk test. ANOVA test for normal distribution and Kruskal-Wallis test for non-parametric distribution were used to compare experimental data. The multiple comparisons were performed with Tukey's post-hoc test for normal distribution and Dunn's post-hoc test for non-parametric distribution. Paired Student's t-test for normal distribution and Wilcoxon signed-rank test for non-parametric distribution were used to compare two related samples. Student's t test for normal distribution and Mann-Whitney $U$ test for non-parametric distribution were used to compare two independent samples. The Spearman correlation coefficient (R) was applied to present the strength of the relationship between variables (Statistica, version 12; Statsoft, Tulsa, OK, USA). Differences or correlations with $p<0.05$ were considered as statistically significant.

\section{Results}

Expression of SIRT1 in CD56dim and CD56bright cells

The gating strategy performed for NK cell subsets of the young, old and the oldest is demonstrated in Fig. 1 and flow cytometry analysis scheme is shown in Fig. 2. Flow cytometry data were analyzed and presented in two ways, i.e. as percentages of CD56dim and CD56bright cells with the expression of the studied protein (\% of positive cells) and relative expression, i.e. mean fluorescence intensity (MFI) measured in the analyzed samples.

Flow cytometry data analysis performed in the young and the old (seniors at the age under 85 ) revealed that the expression of SIRT1 was rather low in non-stimulated CD56dim and CD56bright cells. Both subsets, however, were sensitive to stimulation with IL-2 and PMA with ionomycin, which was particularly observed in the young in the analysis of the percentages of positive cells as well as in relative expression (Fig. 3a-d). CD56bright cells of the old analyzed with the MFI method additionally revealed sensitivity to stimulation by LPS (Fig. 3d). This tendency was found also in the relevant analysis of the percentages of positive cells (Fig. 3b). CD56dim cells of the old were practically insensitive to stimulation except for IL-2 stimulation in MFI analysis, not found in the analysis of percentages (Fig. 3a, c).

Both subsets of NK cells in the young presented a slightly increased level of SIRT1 expression in stimulated cells compared to non-stimulated ones (Fig. 3a-d). However, after comparison of similarly treated CD56dim vs. CD56bright cells, we found it significantly higher in CD56bright cells both without stimulation and upon stimulation with IL-2, LPS or PMA and ionomycin (Table 1). In the old CD56bright cells were more sensitive to stimulation than CD56dim ones (Fig. 3d). However, the expression of SIRT1 in CD56bright cells of the old was higher compared to similarly treated CD56dim cells only upon stimulation with LPS (Table 1).

Non-stimulated CD56dim and CD56bright cells of the oldest seniors showed significantly increased expression of SIRT1 compared with the young and the old (Fig. 3a-d). There were not observed any significant differences between non-stimulated and stimulated CD56dim and bright cells in the analysis of the percentages of positive cells (Fig. 3a, b). However, the analysis of the relative expression revealed in the oldest increased level of SIRT1 upon stimulation with IL-2 and PMA with ionomycin in CD56bright cells (Fig. 3d), not observed in CD56dim cells (Fig. 3c).

\section{Expression of HSP70 $0^{\text {intracellular in CD56dim and }}$ CD56bright cells}

The pattern of HSP70 ${ }^{\text {intracellular }}$ expression in CD56dim and CD56bright cells resembled the expression of SIRT1 in the young and the old. It was rather low in non-stimulated 


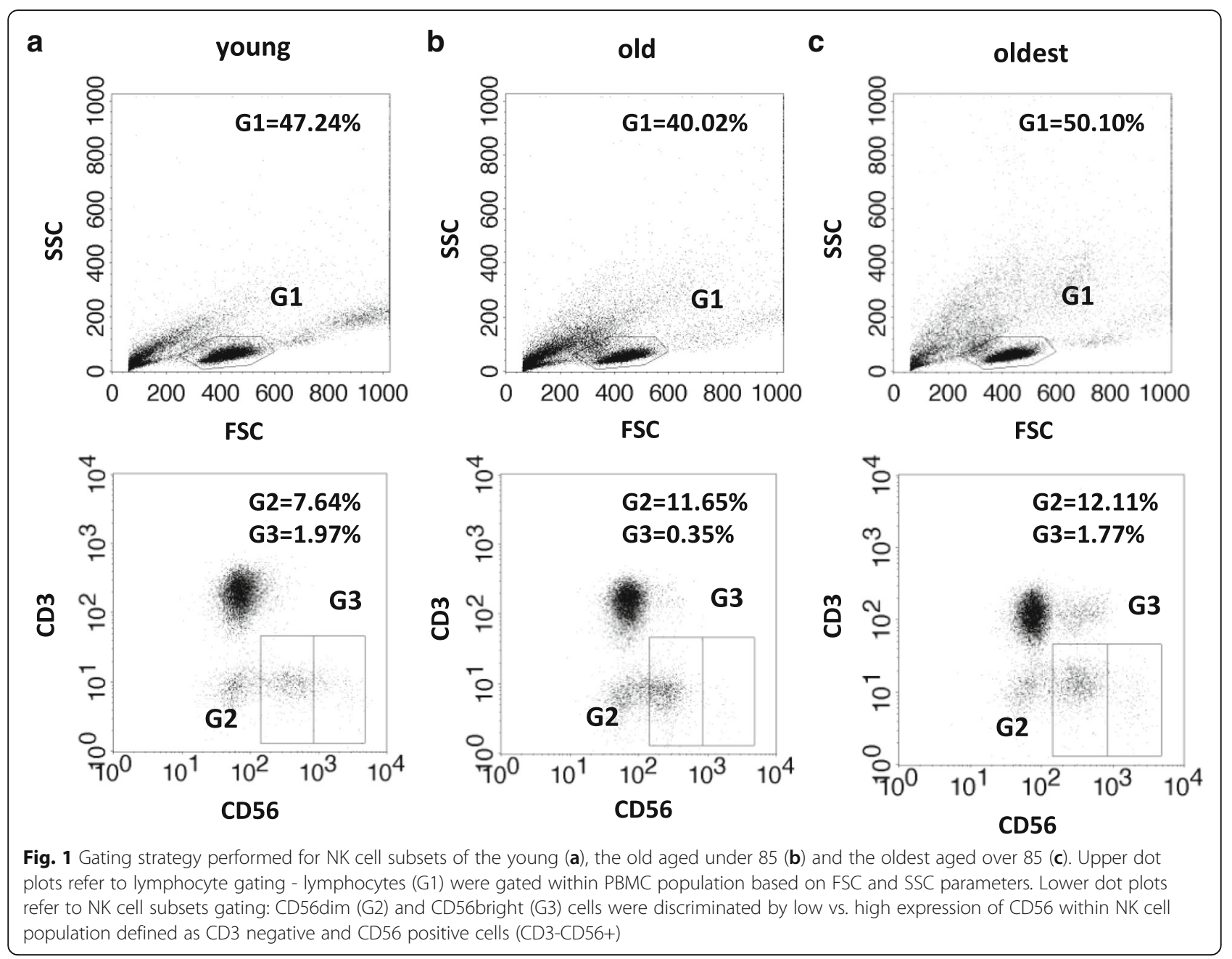

cells, however, both subsets of NK cells were sensitive to stimulation by IL-2 and PMA with ionomycin (Fig. 4a-d). CD56bright cells of the old presented the highest sensitivity and responded to all three types of stimulation observed in the analysis of the percentages of positive cells as well as relative expression (Fig. 4b, d). Although both subsets of NK cells in the young and the old presented an increased level of intracellular HSP70 expression upon stimulation (Fig. 4a-d), it was significantly higher in CD56bright cells compared to similarly treated CD56dim cells of the young observed in both types of analysis (Table 1). In NK cells of the old, the similar phenomenon was found only after stimulation with PMA and ionomycin when the relative expression was analyzed (Table 1).

Non-stimulated CD56dim and CD56bright NK cells of the oldest seniors showed significantly increased expression of intracellular HSP70 compared with the young and the old (Fig. 4a-d). There were no significant differences between non-stimulated and stimulated CD56dim and CD56bright cells in the analysis of the percentages of positive cells, except for CD56bright cells stimulated with PMA and ionomycin (Fig. 4b). The analysis of the relative expression showed, however, the increased level of HSP70 intracellular in both CD56dim and CD56bright cells treated with PMA and ionomycin and also in CD56bright cells upon stimulation with IL-2 (Fig. 4c, d).

\section{Expression of HSP70 $0^{\text {surface }}$ in CD56dim and CD56bright cells}

$\mathrm{HSP70}^{\text {surface }}$ revealed a quite different pattern of expression in NK cells. It was relatively low in non-stimulated cells, however, sensitive to stimulation by PMA with ionomycin in CD56dim cells of all age groups (Fig. 5a, c). The highest sensitivity to stimulation presented CD56dim cells of the oldest seniors as they increased expression of HSP70 $0^{\text {surface }}$ after stimulation by both IL-2 and PMA with ionomycin in both types of analysis (Fig. 5a, c). However, CD56bright cells were even more sensitive compared to CD56dim cells as they responded to all three types of stimulation in the group of the young and the oldest when the relative expression was measured (Fig. 5d). In the same analysis CD56bright cells of the old responded only to stimulation 


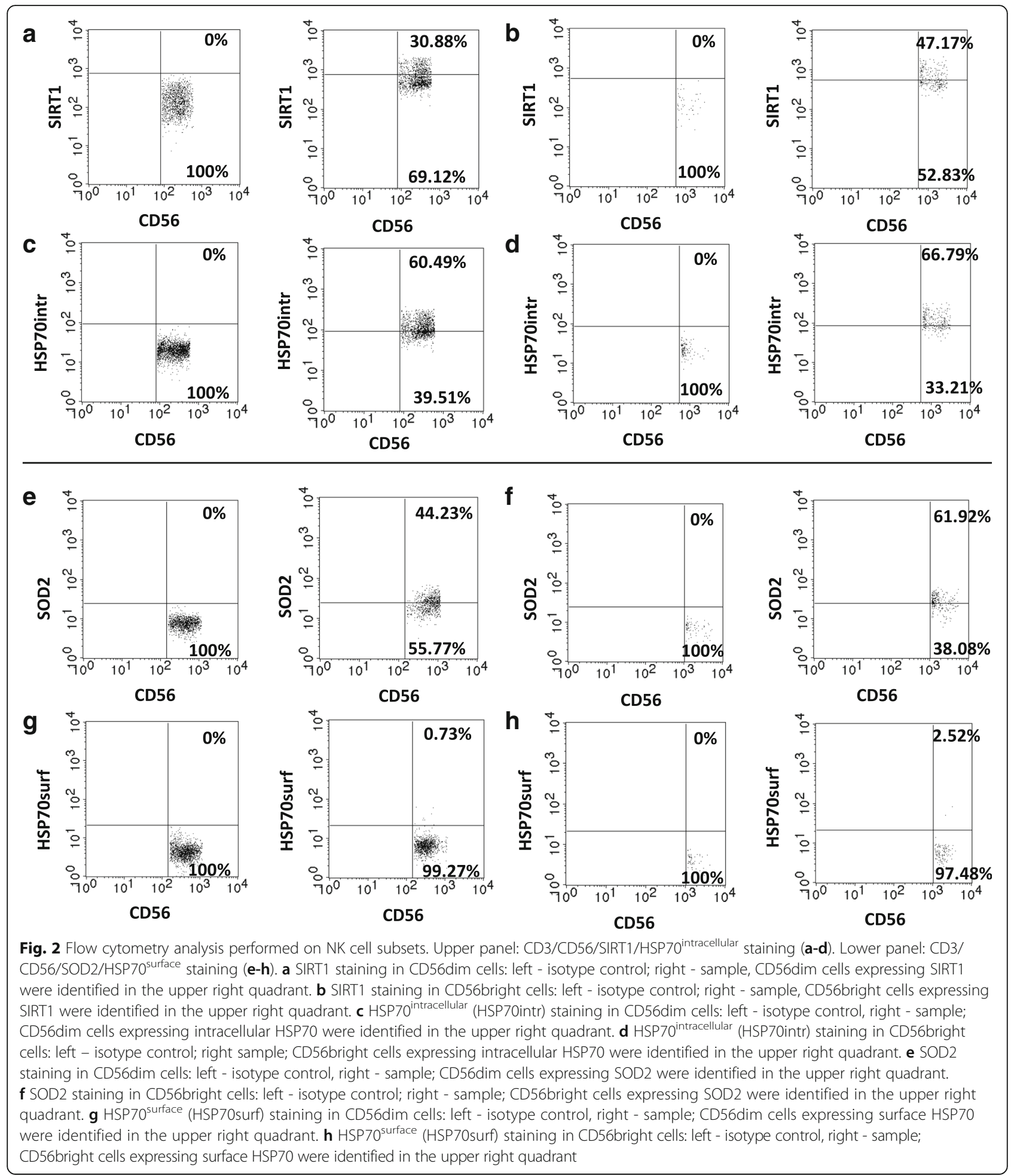

by IL-2 and PMA with ionomycin (Fig. $5 \mathrm{~d}$ ). NK cells generally showed increased level of surface HSP70 expression upon stimulation. In most cases it was significantly higher in CD56dim cells compared to similarly treated CD56bright cells as we observed in all age groups and in both types of analysis (Table 1).
Expression of SOD2 in CD56dim and CD56bright cells

There were no significant differences in the expression of SOD2 between non-stimulated and stimulated CD56dim cells of the young. Then, the sensitivity to stimulation of these cells increased with ageing and in the group of seniors below 85 years CD56dim cells became sensitive to 

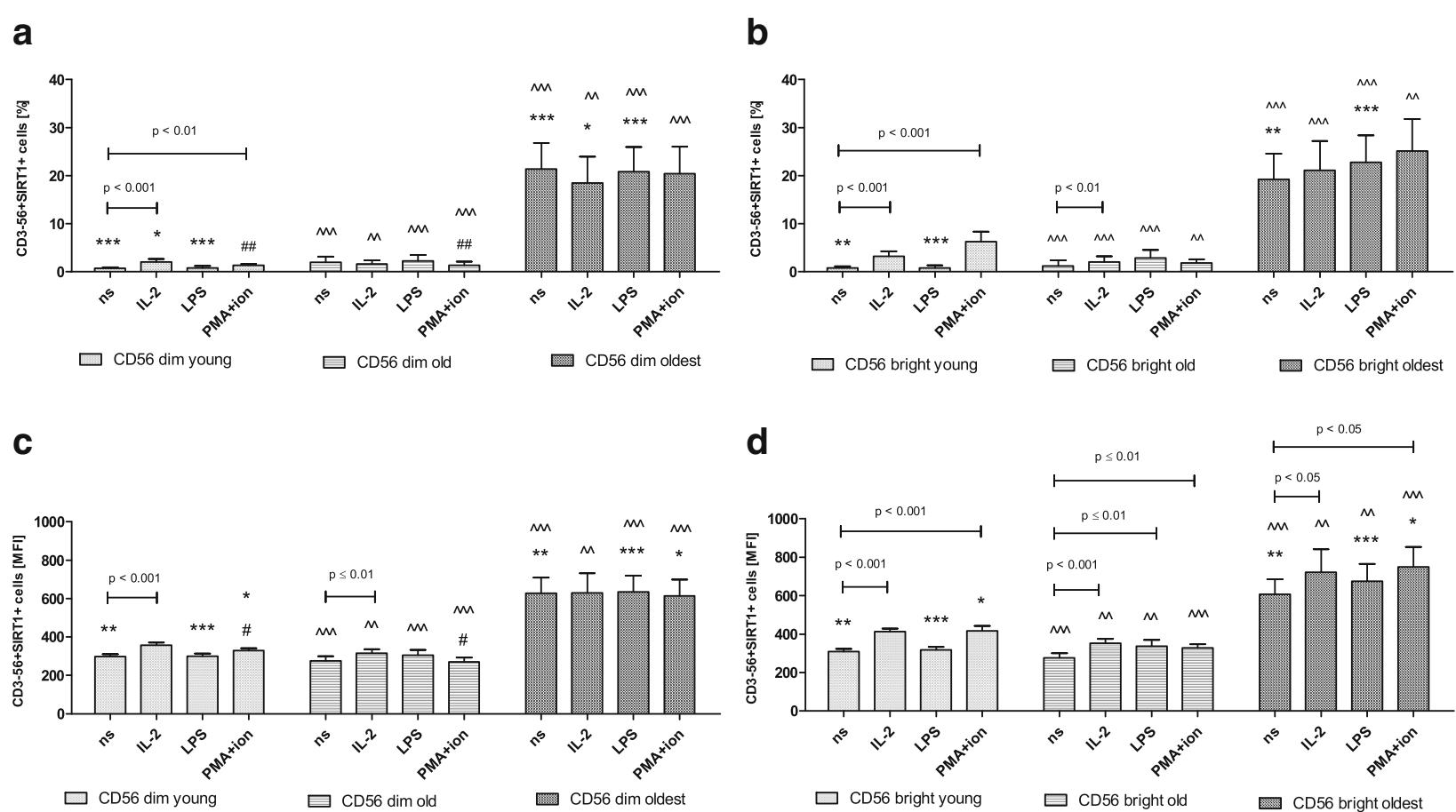

Fig. 3 Expression of SIRT1 in non-stimulated and stimulated CD56dim and CD56bright cells of the young, old and the oldest. Data are presented as means \pm SEM and show expression of the studied protein in NK cell subsets demonstrated as the percentage of cells with the expression of a particular protein (\%) and mean fluorescence intensity (MFI). The same symbols over bars $\left({ }^{*}, *, \wedge\right)$ denote statistically significant differences between similarly treated CD56dim or CD56bright cells, i.e. respectively non-stimulated or stimulated by IL-2, LPS or PMA with ionomycin compared between: young vs. old (marked with ${ }^{*}$ ), young vs. oldest (marked with *) and old vs. oldest (marked with $\wedge$ ). 3 symbols denote $p<0.001 ; 2$ symbols denote $p<0.01 ; 1$ symbol denotes $p<0.05$. Horizontal lines above paired bars denote statistically significant differences between respectively CD56dim or CD56bright cells non-stimulated vs. stimulated by IL-2, LPS or PMA with ionomycin within the same age group. a Expression of SIRT1 in CD56dim cells (\%). b Expression of SIRT1 in CD56bright cells (\%). c Expression of SIRT1 in CD56dim cells (MFI). d Expression of SIRT1 in CD56bright cells (MFI)

stimulation by PMA with ionomycin observed in both types of analysis (Fig. 6a, c). CD56bright cells of the young were sensitive to stimulation by PMA and ionomycin in the analysis of the percentages of positive cells (Fig. 6b) and additionally to IL-2 observed when the analysis of relative expression was performed (Fig. 6d). Similarly, the old revealed in both types of analysis comparable to the young sensitivity of CD56bright cells to the stimulation and responded to IL-2 and PMA with ionomycin (Fig. 6b, d).

NK cell subsets of the oldest seniors presented the highest sensitivity to stimulation, i.e. by IL-2 and PMA with ionomycin in CD56dim cells (Fig. 6a, c) and all three types of stimulation in CD56bright cells found in both types of analysis (Fig. 6b, d). Although the subsets of NK cells, except for CD56dim cells of the young, increased level of SOD2 expression upon most types of stimulation (Fig. 6a-d), it was significantly higher in CD56bright cells of the oldest stimulated with IL-2 and LPS compared to similarly treated CD56dim cells (Table 1). In the group of the old this phenomenon was observed only in CD56bright cells stimulated by IL-2 in MFI analysis (Table 1).

\section{Expression of TNF in CD56dim and CD56bright cells}

The expression of TNF in non-stimulated cells was significantly higher in both CD56dim and CD56bright cells of the oldest compared to the young and the old (Fig. 7a-d). CD56dim cells of all age groups appeared to be sensitive to stimulation by PMA with ionomycin observed both in the analysis of the percentages of positive cells and the relative expression (Fig. 7a, c). Additionally, CD56dim cells of the oldest seniors showed sensitivity to stimulation by IL-2 found in MFI analysis (Fig. 7c). CD56bright cells of all age groups were also sensitive to these two types of stimulation when the analysis of the relative expression was performed (Fig. 7d). Although CD56bright cells appeared to be more sensitive to stimulation, CD56dim cells revealed higher expression of TNF compared to CD56bright ones when similarly treated cells were compared within the analyzed age group (Table 1).

\section{Expression of IFN- $\gamma$ in CD56dim and CD56bright cells}

The pattern of IFN- $\gamma$ expression in CD56dim cells of all age groups resembled the expression of TNF in these cells. However, both CD56dim and CD56bright cells of 
Table 1 Comparison of the analyzed parameters between similarly treated CD56dim and CD56bright cells of the same age group

\begin{tabular}{|c|c|c|c|c|c|c|c|}
\hline \multirow[t]{3}{*}{ Parameter } & \multirow[t]{3}{*}{ Stimulation type } & \multicolumn{6}{|c|}{ CD56dim vs. CD56bright } \\
\hline & & \multicolumn{2}{|l|}{ young } & \multicolumn{2}{|l|}{ old } & \multicolumn{2}{|l|}{ oldest } \\
\hline & & $\%$ & MFI & $\%$ & MFI & $\%$ & MFI \\
\hline \multirow[t]{4}{*}{ SIRT1 } & ns & $\begin{array}{l}* * \\
\uparrow \text { bright }\end{array}$ & - & $\begin{array}{l}* * \\
\uparrow \operatorname{dim}\end{array}$ & - & - & - \\
\hline & IL2 & - & $\begin{array}{l}{ }^{*} \\
\uparrow \text { bright }\end{array}$ & - & - & - & - \\
\hline & LPS & $\begin{array}{l}* * * \\
\uparrow \text { bright }\end{array}$ & - & $\stackrel{*}{\uparrow}$ bright & - & - & - \\
\hline & PMA/ion & - & $\begin{array}{l}*^{* *} \\
\uparrow \text { bright }\end{array}$ & - & - & - & - \\
\hline \multirow[t]{4}{*}{ HSP70 ${ }^{\text {intr }}$} & ns & - & - & - & - & - & - \\
\hline & IL2 & $\stackrel{*}{\uparrow \text { bright }}$ & $\begin{array}{l}{ }^{* *} \\
\uparrow \text { bright }\end{array}$ & - & - & - & - \\
\hline & LPS & - & - & - & - & - & - \\
\hline & PMA/ion & $\stackrel{*}{\uparrow \text { bright }}$ & $\begin{array}{l}{ }^{* *} \\
\uparrow \text { bright }\end{array}$ & - & $\begin{array}{l}* * \\
\uparrow \text { bright }\end{array}$ & - & - \\
\hline \multirow[t]{4}{*}{$\mathrm{HSP} 70^{\text {surf }}$} & ns & $\begin{array}{l}* * * \\
\uparrow \operatorname{dim}\end{array}$ & $\begin{array}{l}* * * \\
\uparrow \operatorname{dim}\end{array}$ & $\begin{array}{l}* * * \\
\uparrow \text { bright }\end{array}$ & $\begin{array}{l}\text { *** } \\
\uparrow \operatorname{dim}\end{array}$ & $\begin{array}{l}{ }^{* * *} \\
\uparrow \operatorname{dim}\end{array}$ & $\begin{array}{l}\text { *** }^{* *} \\
\uparrow \operatorname{dim}\end{array}$ \\
\hline & IL2 & - & - & $\begin{array}{l}\text { *** } \\
\uparrow \operatorname{dim}\end{array}$ & - & $\stackrel{*}{\uparrow} \operatorname{dim}$ & - \\
\hline & LPS & $\begin{array}{l}*^{* *} \\
\uparrow \text { bright }\end{array}$ & $\stackrel{*}{\uparrow} \operatorname{dim}$ & $\begin{array}{l}* * * \\
\uparrow \operatorname{dim}\end{array}$ & - & $\begin{array}{l}* * * \\
\uparrow \operatorname{dim}\end{array}$ & - \\
\hline & PMA/ion & $\begin{array}{l}\text { *** } \\
\uparrow \operatorname{dim}\end{array}$ & $\begin{array}{l}* * * \\
\uparrow \operatorname{dim}\end{array}$ & - & - & - & - \\
\hline \multirow[t]{4}{*}{ SOD2 } & ns & - & - & $\stackrel{* *}{\uparrow} \operatorname{dim}$ & - & - & - \\
\hline & IL2 & - & - & - & $\stackrel{*}{\uparrow \text { bright }}$ & $\begin{array}{l}* * * \\
\uparrow \text { bright }\end{array}$ & $\begin{array}{l}{ }^{* *} \\
\uparrow \text { bright }\end{array}$ \\
\hline & LPS & - & - & - & - & $\begin{array}{l}{ }^{*} \\
\uparrow \text { bright }\end{array}$ & - \\
\hline & PMA/ion & - & - & - & - & - & - \\
\hline \multirow[t]{4}{*}{ TNF } & ns & $\begin{array}{l}* * * \\
\uparrow \text { bright }\end{array}$ & $\begin{array}{l}* * * \\
\uparrow \operatorname{dim}\end{array}$ & $\stackrel{* * *}{\uparrow \operatorname{dim}}$ & $\begin{array}{l}* * * \\
\uparrow \operatorname{dim}\end{array}$ & $\begin{array}{l}\text { *** } \\
\uparrow \text { bright }\end{array}$ & $\begin{array}{l}\text { ** } \\
\uparrow \operatorname{dim}\end{array}$ \\
\hline & IL2 & - & $\begin{array}{l}\text { *** } \\
\uparrow \operatorname{dim}\end{array}$ & - & $\begin{array}{l}\text { *** } \\
\uparrow \operatorname{dim}\end{array}$ & - & - \\
\hline & LPS & $\begin{array}{l}\text { *** } \\
\uparrow \operatorname{dim}\end{array}$ & $\begin{array}{l}{ }^{* * *} \\
\uparrow \operatorname{dim}\end{array}$ & $\begin{array}{l}\text { *** } \\
\uparrow \operatorname{dim}\end{array}$ & $\begin{array}{l}* * * \\
\uparrow \operatorname{dim}\end{array}$ & $\begin{array}{l}* * * \\
\uparrow \operatorname{dim}\end{array}$ & $\begin{array}{l}* * \\
\uparrow \operatorname{dim}\end{array}$ \\
\hline & PMA/ion & $\begin{array}{l}* * * \\
\uparrow \operatorname{dim}\end{array}$ & $\begin{array}{l}* * * \\
\uparrow \operatorname{dim}\end{array}$ & $\begin{array}{l}* * * \\
\uparrow \operatorname{dim}\end{array}$ & $\begin{array}{l}* * * \\
\uparrow \operatorname{dim}\end{array}$ & $\begin{array}{l}* * * \\
\uparrow \operatorname{dim}\end{array}$ & $\begin{array}{l}* * \\
\uparrow \operatorname{dim}\end{array}$ \\
\hline \multirow[t]{4}{*}{$\mathrm{IFN}-\gamma$} & ns & - & - & $\begin{array}{l}\text { *** } \\
\uparrow \operatorname{dim}\end{array}$ & - & - & - \\
\hline & IL2 & - & - & - & - & - & - \\
\hline & LPS & - & - & $\stackrel{* *}{\uparrow} \operatorname{dim}$ & - & - & - \\
\hline & PMA/ion & - & $\stackrel{*}{\uparrow} \operatorname{dim}$ & - & - & $\begin{array}{l}* \\
\uparrow \text { bright }\end{array}$ & - \\
\hline
\end{tabular}

$\uparrow$ denotes significantly higher expression in dim or bright cells

'HSP7O intr' intracellular HSP70, 'HSP70 ${ }^{\text {surfi }}$ surface HSP70, 'PMA/ion' PMA + ionomycin

${ }^{* * *} p<0.001$; ** $p<0.01 ;{ }^{*} p<0.05$

all studied age groups were sensitive to stimulation by IL-2 and PMA with ionomycin what was clearly documented by the relative expression and also to some extent by the analysis of the percentages of positive cells (Fig. 8a-d). The most sensitive to stimulation appeared to be CD56bright cells of the oldest seniors which responded 


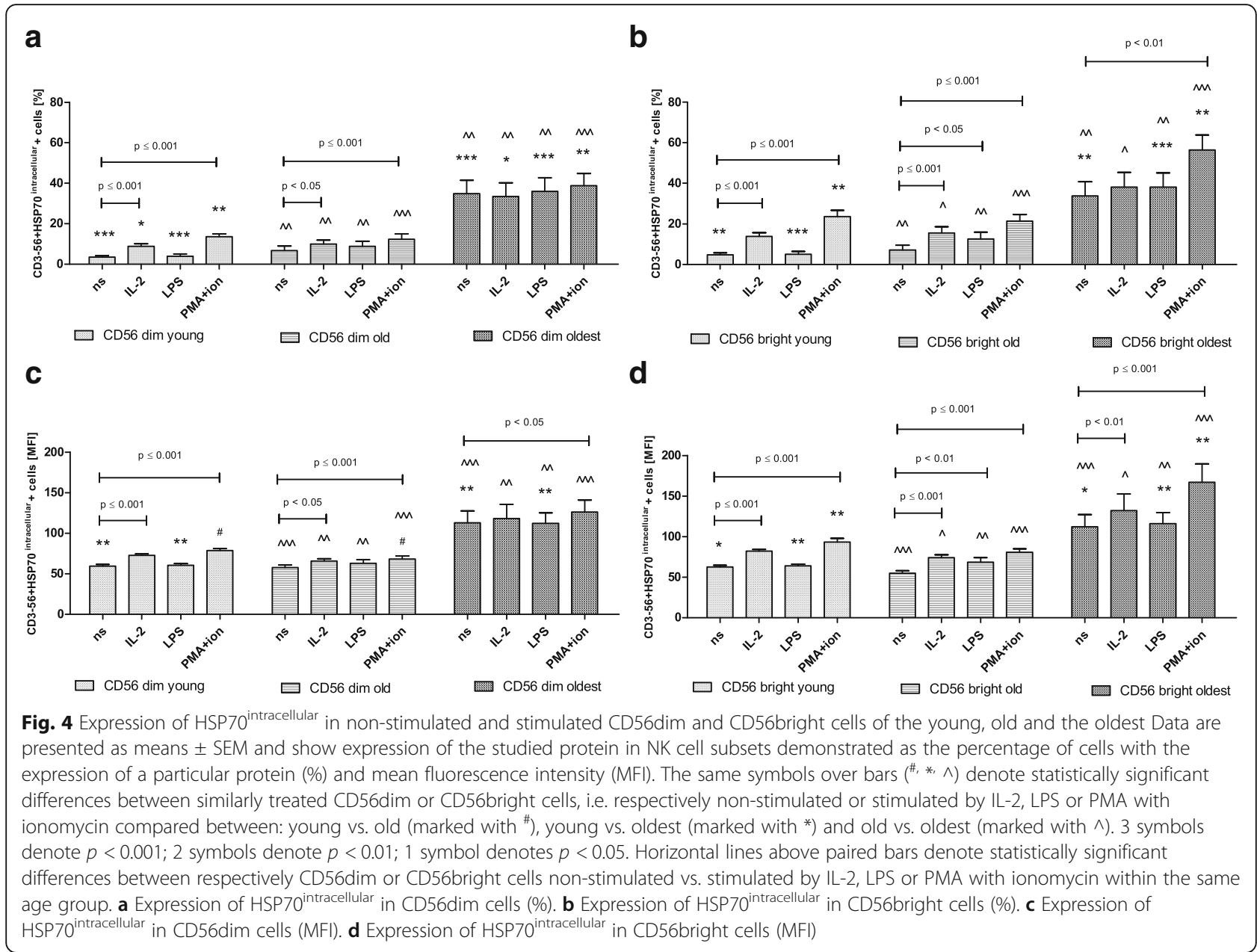

to all types of the applied stimulations shown in the analysis of the relative expression (Fig. 8d). The analysis of the percentages of positive cells revealed the predominance of CD56bright vs. CD56dim cells in expression of IFN $-\gamma$ upon stimulation with PMA and ionomycin observed in the oldest (Table 1). The similar analysis performed in the old and the young showed however higher expression of IFN- $\gamma$ rather in CD56dim cells compared to CD56bright cells (Table 1 ).

\section{Relationships between the analyzed parameters in CD56dim and CD56bright NK cells}

The flow cytometric analysis provided multitude of data what allowed to reveal some relationships between the analyzed parameters. Interestingly, they were observed both in CD56dim and CD56bright cells and corresponded to some extent to those reported earlier by our group in the total NK cell population [47]. Very high positive correlations between SIRT1 and HSP70 ${ }^{\text {intracellular }}$ expression in all studied set-ups of CD56dim cells, i.e. non-stimulated or treated with IL-2, LPS or PMA with ionomycin, were noted (Table 2). Similarly, high and very high positive correlations between these parameters were observed within CD56bright cells (Table 3). Low positive correlations were found between the expression of SIRT1 and: (i) TNF in all applied conditions, (ii) IFN- $\gamma$ in all conditions except for stimulation with PMA + ionomycin in both CD56dim and CD56bright cells and additionally without LPS stimulation in CD56bright cells, (iii) SOD2 in samples stimulated with IL-2 in CD56bright cells and PMA with ionomycin in CD56dim cells and (iv) HSP70 ${ }^{\text {surface }}$ in cells stimulated with IL-2 within the population of CD56 bright cells (Tables 2 and 3 ).

The expression of HSP70 ${ }^{\text {intracellular }}$ revealed relationships similar to these of SIRT1. Low positive correlations were found between the expression of this protein and: (i) TNF in all applied conditions, (ii) IFN- $\gamma$ in all conditions except for stimulation with PMA + ionomycin, (iii) SOD2 in samples stimulated with IL-2 in CD56bright cells and PMA + ionomycin in CD56dim and CD56bright cells, and (iv) HSP70 ${ }^{\text {surface }}$ in cells stimulated with IL-2 in both CD56dim and CD56bright cells (Tables 2 and 3).

The moderate to high correlations between the expression of HSP70 $0^{\text {surface }}$ and SOD2 in all variants of the 


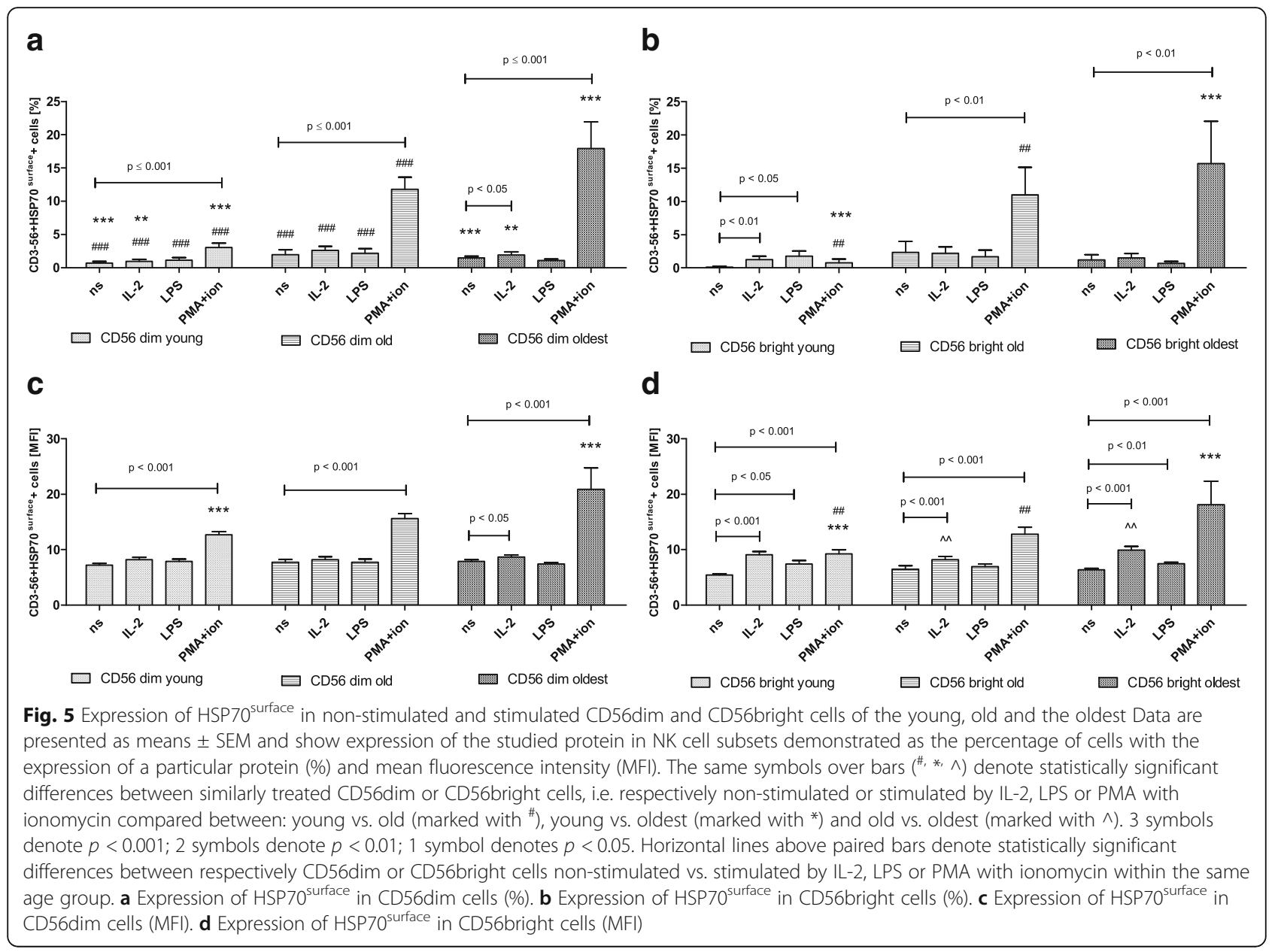

applied conditions were observed in both CD56dim and CD56bright cells in the whole study group. HSP70 $^{\text {surface }}$ expression revealed also some lower correlations with other parameters, i.e.: (i) TNF in all applied conditions in both CD56dim and CD56bright cells and (ii) IFN- $\gamma$ in CD56 bright cells stimulated with IL-2 and in both CD56dim and CD56bright cells stimulated with LPS (Tables 2 and 3). The expression of TNF correlated with: (i) SOD2 in cells stimulated with IL-2 in CD56bright cells and in both CD56dim and CD56bright cells stimulated by PMA with ionomycin (ii) IFN- $\gamma$ in non-stimulated cells and cells treated with IL-2 and LPS in CD56dim cells and in all variants of stimulation in CD56bright cells. Intracellular IFN- $\gamma$ correlated positively with the expression of SOD2 in both CD56dim and CD56bright cells treated with LPS (Tables 2 and 3).

\section{Relationships between the age and the analyzed} parameters studied in CD56dim and CD56bright NK cells

Some of the analyzed parameters correlated with age. Remarkably, the expression of SIRT1 showed positive correlations with age in all studied variants, except for the cells stimulated with IL-2 in both CD56dim and
CD56bright cells. HSP70 ${ }^{\text {intracellular }}$ revealed similar to SIRT1 positive correlations in CD56bright cells. Intracellular HSP70 in CD56dim cells correlated positively with age only in non-stimulated cells and upon stimulation with LPS (Table 4). The expression of TNF revealed low to moderate positive correlations with age in all applied experimental conditions in both CD56dim and CD56bright cells. In CD56bright cells HSP70 ${ }^{\text {surface }}$ correlated positively with age in non-stimulated cells and cells stimulated with LPS and PMA with ionomycin. The expression of HSP70 in CD56 dim cells showed the positive correlation with age only in cells treated with PMA and ionomycin. IFN- $\gamma$ correlated positively with age in cells upon stimulation with IL-2 and PMA with ionomycin in CD56bright cells, but not in CD56dim cells (Table 4).

\section{Discussion}

Data obtained in the presented study for CD56dim and CD56bright cells correspond to our observations performed earlier on the total NK cell population [47]. Thus, similarly to the previous study, the non-stimulated CD56dim and CD56bright cells of the oldest seniors presented significantly higher expression of SIRT1 compared to seniors under 85 


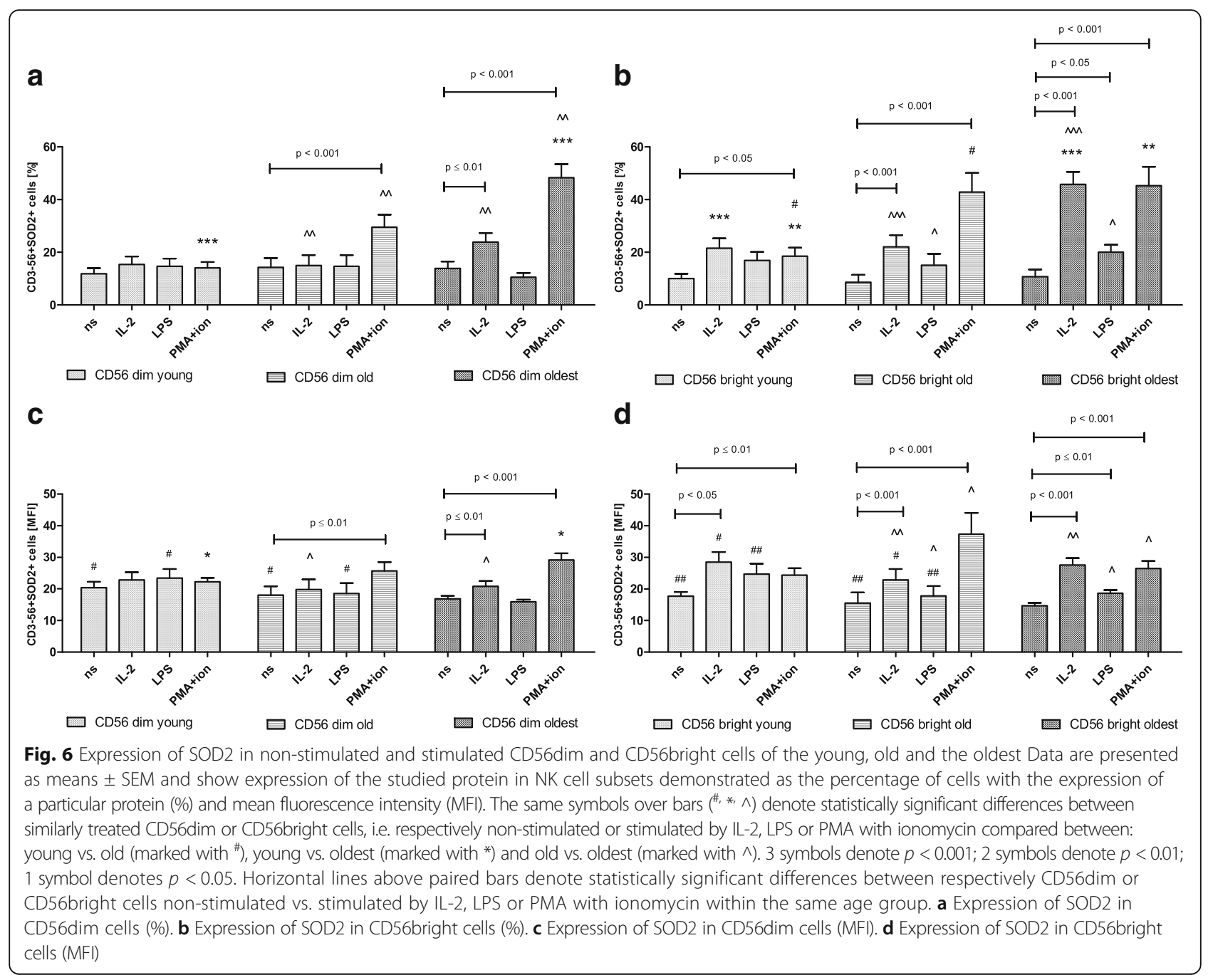

and the young. Correspondingly, results obtained for HSP70 ${ }^{\text {intracellular }}$ expression were very similar to that of SIRT1. CD56dim cells appeared to be insensitive (SIRT1) or nearly insensitive (HSP70 ${ }^{\text {intracellular }}$ ) to the stimulation in the group of the oldest seniors on the contrary to CD56bright cells which in the same age group responded to stimulation by IL-2 and PMA with ionomycin. In the group of seniors under 85 CD56bright cells were also more sensitive to stimulation than CD56dim cells in regard to the expression of both studied cellular protective proteins. In the young both NK cell subsets appeared to be equally sensitive to stimulation. These results may suggest that generally more sensitive to activation CD56bright cells might be involved in rather inducible cellular stress response and this activity seems to be sustained until very advanced age, associated with the increased level of protective proteins in the oldest seniors. The more numerous CD56dim cells [50] were resistant to further stimulation but presented, similarly to CD56bright cells, higher basic expression of cellular protective proteins, i.e. SIRT1 and HSP70. Thus, in the total NK cell population CD56dim cells seem to overshadow the activity of more sensitive to stimulation but much less numerous CD56bright cells [4, 47]. Although both subsets of NK cells presented an increased expression level of SIRT1 and HSP70 ${ }^{\text {intracellular }}$ after stimulation in the population of the young and the old, nevertheless, after comparison of similarly treated CD56dim vs. CD56bright cells, we found this expression significantly higher in CD56bright cells, with no significant differences observed in the oldest.

Very high correlations between SIRT1 and HSP70 $0^{\text {intra- }}$ cellular proteins observed in both CD56dim and CD56bright cells might suggest the presence of regulatory loops involved in the control of their expression. SIRT1 was earlier found to stimulate the expression of HSP70 by deacetylation of HSF1 (heat shock factor 1) [45]. This signaling pathway might explain the strong correlation between the analyzed proteins involved in 


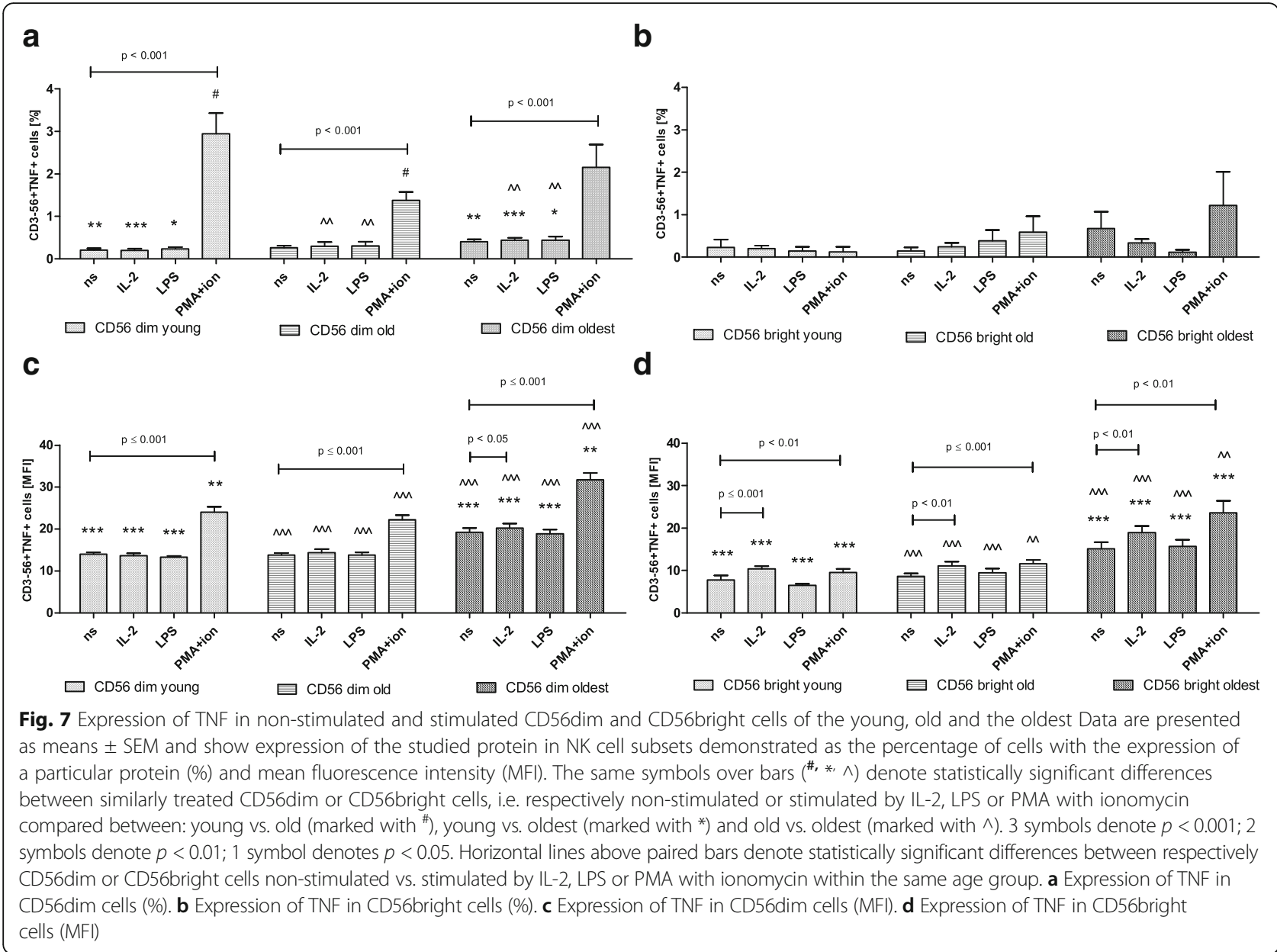

the cellular adaptive response [51]. We observed also the similar correlations in our earlier studies [4, 47].

Although some changes in the level of the expression of cellular protective proteins in ageing were reported, i.e. HSP70 in granulocytes [52], monocytes and lymphocytes [53, 54] or SIRT1-SIRT7 in PBMCs [55], no other study has systematically investigated the effect of ageing on the expression of SIRT1, both forms of HSP70 and SOD2 in two major subpopulations of NK cells.

It is well known that superoxide dismutases are cellular protective enzymes scavenging superoxide generated by mitochondria. The mitochondrial SOD2 is the main antioxidant enzyme that protects cells from oxidative stress [56]. The age-related expression of this dismutase in various human cell types was investigated in skeletal muscle cells [57] and PBMCs [58]. SOD2 expression was analyzed also by our group in ageing human NK cells [4, 47].

The studies performed on skeletal muscle cells of subjects at different age showed the significant increase in SOD2 activity in persons aged between 76 and 85 years as compared to the young (17-25 year-old group) [57] whereas no differences in the levels of SOD2 mRNA were found between young $(25 \pm 2 y)$ and older men $(61 \pm 2$ y) [58]. Similarly to the results of these studies the experiments performed on freshly isolated NK cells demonstrated significantly increased SOD2 expression in both CD56dim and CD56bright cells of the oldest seniors compared to the young and the elderly below the age of 85 [4]. In the present study CD56bright cells showed higher sensitivity to stimulation compared to CD56dim cells in the young and both groups of the elderly. Interestingly, NK cell subsets of the oldest appeared to be the most sensitive to stimulation, with a predominance of CD56bright cells, which responded all three types of stimulation. Thus, we have identified a novel feature of NK cell ageing process: the sensitivity to stimulation resulting in the expression of SOD2 increases with age in both NK cell subsets, although with some prevalence of CD56bright cells. Correspondingly to the expression of both SIRT1 and intracellular HSP70, after comparison of similarly treated CD56bright vs. CD56dim cells within the same age group, higher SOD2 expression was found mostly in CD56bright cells.

We also report age-related differences in the expression of HSP70 ${ }^{\text {surface }}$ in NK cell subsets. Extracellular HSPs act as signaling molecules that activate the immune system in 

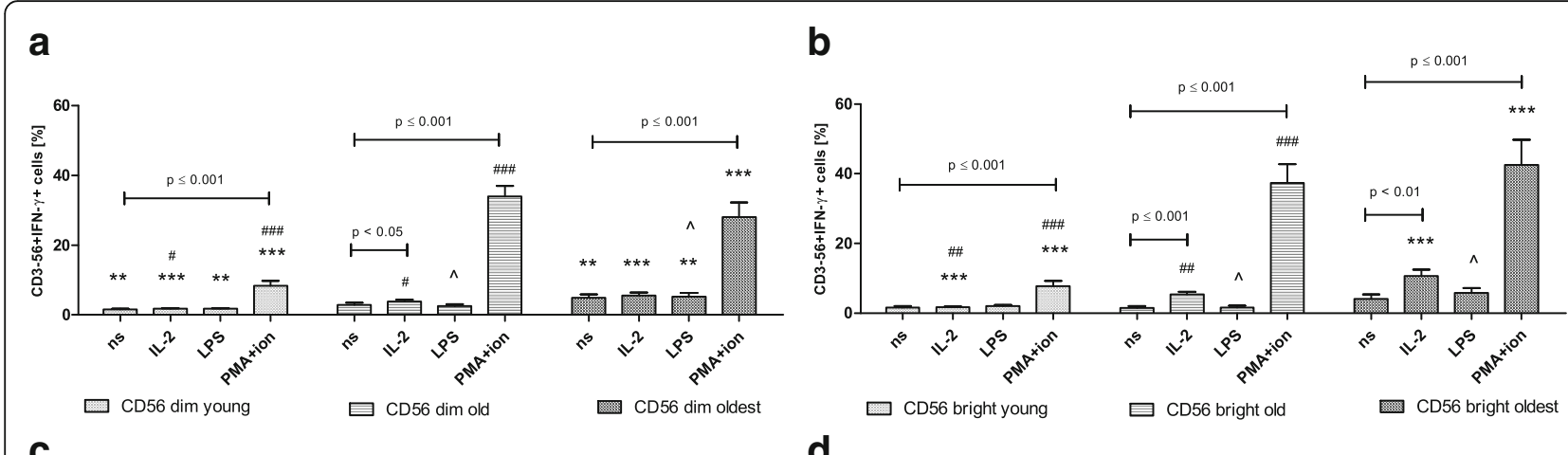

C

d
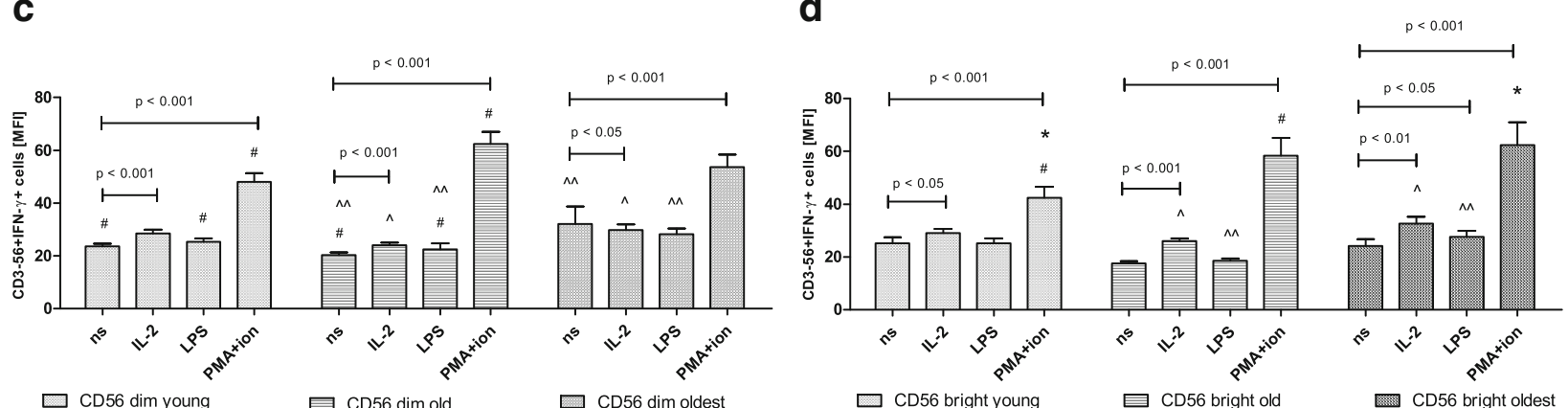

Fig. 8 Expression of IFN- $\gamma$ in non-stimulated and stimulated CD56dim and CD56bright cells of the young, old and the oldest Data are presented as means \pm SEM and show expression of the studied protein in NK cell subsets demonstrated as the percentage of cells with the expression of a particular protein (\%) and mean fluorescence intensity (MFI). The same symbols over bars $(\#, *, \wedge)$ denote statistically significant differences between similarly treated CD56dim or CD56bright cells, i.e. respectively non-stimulated or stimulated by IL-2, LPS or PMA with ionomycin compared between: young vs. old (marked with *), young vs. oldest (marked with *) and old vs. oldest (marked with $\wedge$ ). 3 symbols denote $p<0.001 ; 2$ symbols denote $p<0.01$; 1 symbol denotes $p<0.05$. Horizontal lines above paired bars denote statistically significant differences between respectively CD56dim or CD56bright cells non-stimulated vs. stimulated by IL-2, LPS or PMA with ionomycin within the same age group. a Expression of IFN- $\gamma$ in CD56dim cells (\%). $\mathbf{b}$ Expression of IFN- $\gamma$ in CD56bright cells (\%). $\mathbf{c}$ Expression of IFN- $\gamma$ in CD56dim cells (MFI). $\mathbf{d}$ Expression of IFN- $\gamma$ in CD56bright cells (MFI)

response to stress [59]. The expression of HSP70 in CD56bright cells was more sensitive to stimulation compared to CD56dim cells similarly to HSP70 ${ }^{\text {intracellular }}$. However, on the contrary to HSP70 ${ }^{\text {intracellular }}$, when the expression of HSP70 ${ }^{\text {surface }}$ was compared within the same age group in both studied NK cell subsets stimulated in the same way, it appeared that CD56dim cells presented higher expression compared to CD56bright cells.

It has been previously noted that extracellular HSPs do not contain a signaling sequence for their secretion via the classic ER-Golgi pathway and they likely use an alternative mechanism of the translocation across the plasma membrane [60]. We could not verify the origin of this protein to find whether it is a membrane form of HSP70 produced by NK cells or extracellular HSP70 bound to TLR receptors on the surface of NK cells. The commercially available antibodies are able to recognize only HSPs bound to TLRs on the cell surface rather than the integrated with the cell membrane form of HSP70 [61].

Interestingly, we observed a high correlation between SOD2 and surface HSP70 expression both in CD56dim and CD56bright cells which was found also in freshly isolated cells [4] and in NK cell cultures [47]. The relationship between surface HSP70 and SOD2 is difficult to explain since we were not able to distinguish between membrane and surface form of HSP70. Other authors in studies performed on PAECs (pulmonary artery endothelial cells) reported interactions between cytosolic stress-inducible HSP70 and SOD2 to maintain this enzyme in an import-competent, unfolded conformation crucial for its transport into the mitochondria [62, 63]. Further studies on transfected PAECs identified HSP70-binding site in SOD2 molecule essential for the interaction of both molecules [64]. However, these findings described the interactions between SOD2 and intracellular form of HSP70. The relationships between these two particular proteins in the previously studied by our group total population of NK cells were rather low and found only in cells stimulated by IL-2 or PMA with ionomycin [47]. Those results, however, were similar to the present study in regards to CD56bright cells as in CD56dim cells the low positive correlation between HSP70 $^{\text {intracellular }}$ and SOD2 was found only upon stimulation by PMA with ionomycin.

We also observed that the level of HSP70 ${ }^{\text {surface }}$ expression was many times lower than that of HSP70 ${ }^{\text {intracellular. These }}$ data may indicate that the studied cells were not involved in 
Table 2 Correlation analysis of the study population performed for CD56dim cells

\begin{tabular}{|c|c|c|c|c|c|c|}
\hline \multicolumn{7}{|l|}{ CD56dim } \\
\hline Parameter & Stimulation type & SOD2 & SIRT1 & HSP70 intr & HSP70 surf & TNF \\
\hline \multirow[t]{4}{*}{ SIRT1 } & none & ns & & & & \\
\hline & $\mathrm{IL}-2$ & ns & & & & \\
\hline & LPS & ns & & & & \\
\hline & PMA/ion & 0.221 & & & & \\
\hline \multirow[t]{4}{*}{ HSP70 ${ }^{\text {intr }}$} & none & ns & 0.968 & & & \\
\hline & $\mathrm{IL}-2$ & ns & 0.948 & & & \\
\hline & LPS & ns & 0.973 & & & \\
\hline & PMA/ion & 0.296 & 0.929 & & & \\
\hline \multirow[t]{4}{*}{ HSP70 $0^{\text {surf }}$} & none & 0.646 & ns & ns & & \\
\hline & $\mathrm{IL}-2$ & 0.740 & ns & 0.230 & & \\
\hline & LPS & 0.716 & ns & ns & & \\
\hline & PMA/ion & 0.652 & ns & ns & & \\
\hline \multirow[t]{4}{*}{ TNF } & none & ns & 0.391 & 0.423 & 0.244 & \\
\hline & $\mathrm{IL}-2$ & ns & 0.266 & 0.337 & 0.406 & \\
\hline & LPS & ns & 0.372 & 0.385 & 0.301 & \\
\hline & PMA/ion & 0.413 & 0.413 & 0.393 & 0.426 & \\
\hline \multirow[t]{4}{*}{ IFN- $\gamma$} & none & ns & 0.407 & 0.453 & ns & 0.295 \\
\hline & IL-2 & ns & 0.425 & 0.481 & ns & 0.245 \\
\hline & LPS & 0.265 & 0.370 & 0.431 & 0.371 & 0.333 \\
\hline & PMA/ion & ns & ns & ns & ns & ns \\
\hline
\end{tabular}

All values are presented as statistically significant $(p<0.05)$ Spearman's correlation coefficients (R). ' $n s^{\prime}$ denotes statistically not significant

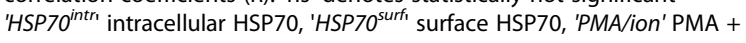
ionomycin

enhanced inflammatory response. It has been previously suggested that extracellular HSP70 can induce proinflammatory cytokine production $[65,66]$. Further studies revealed, however, rather anti-inflammatory properties of extracellular HSP70 and its downregulating effect on the production of proinflammatory cytokines [67-69]. In our studies the expression levels of proinflammatory cytokines (TNF and IFN- $\gamma$ ) were rather low, comparable with these present in non-stimulated cells analyzed shortly after blood sample collection [4]. The highly increased expression of $\mathrm{HSP}^{\text {surface }}$ in both CD56dim and CD56bright cells was observed in both groups of seniors only after stimulation with PMA and ionomycin, a stronger stimulatory agent compared to other used in the study.

Then we found that the expression of TNF in non-stimulated and stimulated CD56dim and CD56bright cells was significantly higher in the oldest compared to the young and the old. The process of ageing is characterized by an elevated proinflammatory status, accompanied by increased levels of different inflammatory mediators in apparently healthy people, e.g. CRP, extracellular HSP70, IL-1, IL-6, TNF [70]. Interestingly, both
Table 3 Correlation analysis of the study population performed for CD56bright cells

\begin{tabular}{|c|c|c|c|c|c|c|}
\hline \multicolumn{7}{|l|}{ CD56bright } \\
\hline Parameter & Stimulation type & SOD2 & SIRT1 & HSP70intr & HSP70 ${ }^{\text {surf }}$ & TNF \\
\hline \multirow[t]{4}{*}{ SIRT1 } & none & ns & & & & \\
\hline & IL-2 & 0.235 & & & & \\
\hline & LPS & ns & & & & \\
\hline & PMA/ion & ns & & & & \\
\hline \multirow[t]{4}{*}{ HSP70 intr } & none & ns & 0.888 & & & \\
\hline & $\mid \mathrm{L}-2$ & 0.240 & 0.958 & & & \\
\hline & LPS & ns & 0.966 & & & \\
\hline & PMA/ion & 0.263 & 0.820 & & & \\
\hline \multirow[t]{4}{*}{ HSP70 surf } & none & 0.576 & ns & ns & & \\
\hline & $\mid \mathrm{L}-2$ & 0.880 & 0.296 & 0.322 & & \\
\hline & LPS & 0.750 & ns & ns & & \\
\hline & PMA/ion & 0.739 & ns & ns & & \\
\hline \multirow[t]{4}{*}{ TNF } & none & ns & 0.409 & 0.391 & 0.263 & \\
\hline & IL-2 & 0.234 & 0.271 & 0.298 & 0.415 & \\
\hline & LPS & ns & 0.424 & 0.430 & 0.220 & \\
\hline & PMA/ion & 0.263 & 0.236 & 0.411 & 0.302 & \\
\hline \multirow[t]{4}{*}{ IFN- $\gamma$} & none & ns & 0.310 & 0.274 & ns & ns \\
\hline & IL-2 & ns & 0.261 & 0.306 & 0.248 & 0.221 \\
\hline & LPS & 0.254 & ns & 0.319 & 0.296 & 0.414 \\
\hline & PMA/ion & ns & ns & ns & ns & 0.302 \\
\hline
\end{tabular}

All values are presented as statistically significant $(p<0.05)$ Spearman's correlation coefficients (R). ' $n s^{\prime}$ denotes statistically not significant 'HSP70 intr' intracellular HSP70, 'HSP70 ${ }^{\text {surf }}$ surface HSP70, 'PMA/ion' PMA + ionomycin

subsets of NK cells of the oldest seniors appeared to be the most sensitive populations to stimulation as was shown in the analysis of the relative expression of these cytokines. The same method of analysis revealed in the old and the young higher sensitivity to stimulation in CD56bright cells compared to CD56dim cells. However, when a comparison of TNF expression between similarly treated CD56dim vs. CD56bright cells within the same age group was performed, a higher expression was observed in CD56dim cells because of its higher basal level in these cells. It is an interesting observation as, generally, CD56bright cells are thought to be the major source of cytokines and CD56dim cells are rather specialized for cytotoxic function [71]. However, upon target cell recognition CD56dim cells could become also more efficient producers of cytokines (e.g. TNF and IFN- $\gamma$ ) than CD56bright NK cells [13]. The process of cytokine secretion by CD56dim cells may be additionally potentiated by exogenous cytokines [72].

IFN- $\gamma$ presented a slightly different pattern of expression. In CD56dim cells it resembled the expression of TNF. Although both NK cell subsets were sensitive to 
Table 4 Correlation analysis of the study population performed for CD56dim and CD56bright cells (age vs. the analyzed parameters)

\begin{tabular}{|c|c|c|c|c|c|c|c|}
\hline \multicolumn{8}{|c|}{ Compared parameter } \\
\hline Parameter & Stimulation type & SOD2 & SIRT1 & HSP70 intr & HSP70 $0^{\text {surf }}$ & TNF & $\mathrm{IFN}-\gamma$ \\
\hline \multicolumn{8}{|l|}{ CD56dim } \\
\hline \multirow[t]{4}{*}{ Age } & none & -0.229 & 0.289 & 0.295 & ns & 0.451 & ns \\
\hline & IL-2 & ns & ns & ns & ns & 0.499 & ns \\
\hline & LPS & ns & 0.409 & 0.399 & ns & 0.534 & ns \\
\hline & PMA/ion & 0.219 & 0.263 & ns & 0.470 & 0.324 & ns \\
\hline \multicolumn{8}{|l|}{ CD56bright } \\
\hline \multirow[t]{4}{*}{ Age } & none & -0.228 & 0.281 & 0.226 & 0.239 & 0.554 & ns \\
\hline & IL-2 & ns & ns & ns & ns & 0.518 & 0.241 \\
\hline & LPS & ns & 0.417 & 0.391 & 0.277 & 0.621 & ns \\
\hline & PMA/ion & ns & 0.235 & 0.345 & 0.421 & 0.439 & 0.355 \\
\hline
\end{tabular}

All values are presented as statistically significant $(p<0.05)$ Spearman's correlation coefficients (R). 'ns' denotes statistically not significant 'HSP70 intr' intracellular HSP70, 'HSP70 ${ }^{\text {surf' }}$ surface HSP70, 'PMA/ion' PMA + ionomycin

stimulation by IL-2 and PMA with ionomycin in all age groups, the highest sensitivity to stimulation was observed in CD56bright cells of the oldest. Analogously, the comparison of similarly treated CD56dim vs. CD56bright cells performed within the same age group revealed higher expression of IFN- $\gamma$ in CD56bright cells. The similar analysis performed in the young and the old showed, however, a predominance of CD56dim cells. These results corresponded to our previously obtained data for freshly isolated cells [4]. CD56bright cells act as immunomodulatory cells in NK cell population but their number decreases with age [73]. Data obtained in our studies might indicate a presence of a compensatory mechanism that maintains the immunoregulatory function of NK cells until very advanced age.

Our results correspond also to some extent with data obtained by De Maria and coworkers [14]. They showed that CD56dim cells could produce IFN- $\gamma$ two hours after activation and then the amount of cells with the expression of intracellular IFN- $\gamma$ increased within 4-8 h and afterwards decreased to be non-detectable $16 \mathrm{~h}$ after stimulation. On the contrary, CD56bright cells started IFN- $\gamma$ production later than $16 \mathrm{~h}$ after stimulation [14]. These data describing IFN- $\gamma$ expression in NK cells at short intervals after stimulation resemble our data obtained for the young and the old whereas data on the expression of IFN- $\gamma$ at later intervals after stimulation seem to correspond to our data obtained for the stimulated CD56bright cells of the oldest. These observations correspond also with our results obtained for freshly isolated NK cells; i.e. short stimulation corresponds with higher expression of IFN- $\gamma$ in CD56dim cells of the young and longer stimulation corresponds with relatively higher expression of IFN- $\gamma$ in CD56bright cells of both groups of seniors compared to CD56dim cells [4]. Based on these results we assume that both ageing and NK cell stimulation might influence the level of IFN- $\gamma$ expression in CD56dim and CD56bright cells. Unfortunately, De Mario et al. did not mention the age of the volunteers involved in the study which might be crucial to compare theirs and ours results. The Italian group, however, underlined a different role of two subsets of NK cells, i.e. involvement of more numerous CD56dim cells in rapid (within hours) immunological reactions typical of frontline innate responses and an immunoregulatory role of CD56bright cells which started to produce cytokines at later intervals. CD56bright NK cells are less numerous but their role may be crucial for the maintenance of the immune homeostasis in healthy ageing [14, 73].

The expression of TNF and IFN- $\gamma$ correlated positively with SIRT1 and HSP70 ${ }^{\text {intracellular }}$ in both CD56dim and CD56bright cells. The expression of TNF is under control of NF-kB, a transcription factor involved in the regulation of the inflammatory response [74, 75]. The relationships between SIRT1 activity and TNF secretion were reported in experiments carried out on human monocyte-macrophage cell line MonoMac6. These results showed that activators of SIRT1 downregulated and its inhibitors upregulated release of proinflammatory mediators, such as TNF and IL-8, via NF- $\kappa B$ signaling pathway [76] which might explain the relationships found in our study. The similar relationships were also observed in transgenic SIRT1 mice. They were protected from hepatic inflammation caused by high-fat diet with modest overexpression of SIRT1 which reduced expression of proinflammatory cytokines such as TNF and IL-6 [77].

IFN- $\gamma$ expression is under control of different than TNF transcription factors, i.e. NFAT, PKC-theta, cJUN / AP-1 [78-80]. However, NF-kB site was also identified within the promoter region of IFN- $\gamma$ gene demonstrating that NF-kB may be involved in the molecular mechanisms controlling gene transcription of IFN- $\gamma$ in human T lymphocytes [78] which could directly explain the relationships between SIRT1 and IFN- $\gamma$ observed in our studies. This 
signaling pathway was then confirmed in other studies performed on human NK-92 cells [81, 82].

Surface HSP70, despite a rather low expression, revealed some correlations with TNF in all applied conditions both in CD56dim and CD56bright cells observed also in stimulated NK cells cultured in vitro [47]. As we did not analyze the origin of surface HSP70 (intracellular vs. extracellular), we could only hypothesize the reasons for these correlations. Supposing the extracellular origin, HSPs can act as indicators of the stress conditions and prime the other cells, principally of the immune system, to suppress the propagation of the injury [59]. In this case, the binding of extracellular HSP70 to TLRs on the surface of NK cells can stimulate the secretion of proinflammatory cytokines synthesized by these cells, i.e. TNF and IFN- $\gamma$. The similar positive correlations between extracellular HSP70 and TNF were observed by Krause and colleagues in plasma samples of the elderly (mean age 63.4 \pm 4.4 years) in their studies on insulin resistance [83]. In other studies extracellular HSP70 was found to stimulate IFN- $\gamma$ production in NK cells, however, dendritic cell-NK cell crosstalk with direct cell-cell contact was crucial to initiate this process [84].

Most of the analyzed parameters correlated with age both in CD56dim and CD56bright cells, i.e. the expression of cellular protective proteins (SIRT1 and HSP70 intracellular), TNF and partly $\mathrm{HSP}^{\text {surface }}$ on the contrary to IFN- $\gamma$ which correlated with age in CD56bright cells only. These results correspond to our previous data concerning NK cells [47] and results of the other groups, e.g. the increase in the expression of SIRT1 or HSP70 ${ }^{\text {intracellular }}$ was observed in serum samples [85] or PBMCs [54] of the elderly, respectively. Similarly, an increase in the concentrations of TNF and IFN- $\gamma$ in sera of the elderly was found in our earlier studies [86] and also was reported by other groups [87].

\section{Conclusions}

The results of our study provide some novel observations concerning the expression of cellular protective proteins: SIRT1, HSP70 and SOD2 in human CD56dim and CD56bright NK cells in regards to the process of ageing. SIRT1 and HSP70 expression appeared to be constantly increased in CD56dim cells of the oldest seniors, which, on the contrary to CD56bright cells, were practically insensitive to further stimulation. CD56bright cells also presented an increased expression of these cellular protective proteins in the oldest but, additionally, they also maintained sensitivity to stimulation until very advanced age. In the young and the old both NK cell subsets showed lower than in the oldest expression level of the studied protective proteins but responded to stimulation by most of the applied agents with some prevalence both in the sensitivity and expression level of CD56bright cells. The oldest seniors did not present an increased level of SOD2 expression but it was significantly elevated in both NK cell subsets after stimulation. The sensitivity to stimulation increased with age and was the highest in the oldest with some predominance of CD56bright cells in this process.

The stimulation of NK cells resulted also in higher expression of surface HSP70 and proinflammatory cytokines, i.e. TNF and IFN- $\gamma$. Both CD56dim and CD56bright cells were sensitive to most of the applied types of stimulation until the advanced age. The level of TNF expression after stimulation was higher in CD56dim cells rather than in CD56bright cells and increased with age. Similarly CD56dim cells of the young and the old revealed higher expression of IFN $-\gamma$ after stimulation. It changed, however, in the oldest who revealed higher expression of IFN- $\gamma$ in stimulated by PMA and ionomycin CD56bright cells.

Our results clearly show that both subpopulations of NK cells, i.e. CD56dim and CD56bright cells, play different roles in the process of ageing. CD56bright cells seem to be involved in inducible stress response as they can respond to stimulation until very advanced age and simultaneously increase, similarly to CD56dim cells, the basal level of cellular protective proteins SIRT1 and HSP70 ${ }^{\text {intracellular }}$ in the oldest seniors. CD56dim cells represent both inducible stress response after stimulation in the young and seniors under 85 and rather constant adaptive response in the oldest with higher basal levels of cellular protective proteins insensitive to further stimulation. In conclusion, our study revealed the adaptation of NK cells to stress response in the oldest seniors which might accompany the process of immunosenescence and contribute to the long lifespan of this group of the elderly.

\section{Abbreviations}

ADL: Activities of daily living; CRP: C reactive protein; ERK: Extracellular signal-regulated kinase; FOXO: Forkhead transcription factor class $\mathrm{O}$; GM-CSF: Granulocyte macrophage colony - stimulating factor; HSF: Heat shock factor; HSP: Heat shock protein; MCP: Macrophage chemoattractant protein; MFI: Mean fluorescence intensity; MIP: Macrophage inflammatory protein; MKK: Mitogen - activated protein kinase kinase; MMSE: Mini mental state examination; NF-kB: Nuclear factor kappa-light-chain-enhancer of activated B cells; NSAID: Non-steroid anti-inflammatory drug; PGC: peroxisome proliferator - activated receptor gamma coactivator; PKC: Protein kinase $C_{i}$ PMA: Phorbol myristate acetate; RANTES: Regulated on activation, normal T cell expressed and secreted; SIRT: Sirtuin; SOD: Superoxide dismutase; STAT: Signal transducer and activator of transcription; TLR: Toll-like receptor

\section{Acknowledgements}

Not applicable.

\section{Funding}

This study was supported by the National Science Centre, Poland (grant N N404 597640) and by ST-12 internal funds of the Medical University of Gdańsk, Poland.

\section{Availability of data and materials}

The datasets generated and/or analyzed during the current study are not publicly available due to privacy reasons, but are available in anonymized form from the corresponding author on reasonable request.

\section{Authors' contributions}

LK conceived the project, performed flow cytometry experiments, analyzed and interpreted the data and wrote the manuscript, JF qualified young and old subjects to the project and participated with DS in project development, 
ZK supervised the project performance, analyzed the data and prepared with LK the final version of the article. All authors approved the final version of the manuscript.

\section{Ethics approval and consent to participate}

All volunteers signed informed consent and study received approval from Ethical Committee of the Medical University of Gdańsk, Poland (225/2010).

\section{Consent for publication}

Not applicable.

\section{Competing interests}

The authors declare that they have no competing interests.

\section{Publisher's Note}

Springer Nature remains neutral with regard to jurisdictional claims in published maps and institutional affiliations.

\section{Author details}

${ }^{1}$ Department of Histology, Medical University of Gdańsk, Dębinki 1, 80-211 Gdańsk, Poland. '2Department of Social and Clinical Gerontology, Medical University of Gdańsk, Dębinki 1, 80-211 Gdańsk, Poland. ${ }^{3}$ Department of Pharmacology, Medical University of Gdańsk, Dębowa 23, 80-204 Gdańsk, Poland.

\section{Received: 7 August 2018 Accepted: 2 November 2018}

\section{Published online: 28 November 2018}

\section{References}

1. Cording S, Medvedovic J, Aychek T, Eberl G. Innate lymphoid cells in defense, immunopathology and immunotherapy. Nat Immunol. 2016;17:755-7.

2. Campos C, Pera A, Lopez-Fernandez I, Alonso C, Tarazona R, Solana R. Proinflammatory status influences NK cells subsets in the elderly. Immunol Lett. 2014:162:298-302.

3. Cooper MA. Teach your NK cells well. Immunity. 2016;45:229-31.

4. Kaszubowska L, Foerster J, Kaczor JJ, Schetz D, Ślebioda TJ, Kmieć Z Expression of cellular protective proteins SIRT1, HSP70 and SOD2 correlates with age and is significantly higher in NK cells of the oldest seniors. Immun Ageing. 2017;14:3

5. Hayhoe RPG, Henson SM, Akbar AN, Palmer DB. Variation of human natural killer cell phenotypes with age: identification of a unique KLRG1-negative subset. Hum Immunol. 2010;71:676-81.

6. Lutz CT, Karapetyan A, Al-Attar A, Shelton BJ, Holt KJ, Tucker JH, et al. Human NK cells proliferate and die in vivo more rapidly than $T$ cells in healthy young and elderly adults. J Immunol. 2011;186:4590-8.

7. Hazeldine J, Hampson P, Lord JM. Reduced release and binding of perforin at the immunological synapse underlies the age-related decline in natural killer cell cytotoxicity. Aging Cell. 2012;11:751-9.

8. Almeida-Oliveira A, Smith-Carvalho M, Porto LC, Cardoso-Oliveira J, Ribeiro A dos S, Falcão RR, et al. Age-related changes in natural killer cell receptors from childhood through old age. Hum Immunol. 2011;72:319-29.

9. Lam VC, Lanier LL. NK cells in host responses to viral infections. Curr Opin Immunol. 2017:44:43-51.

10. Vivier E, Raulet $\mathrm{DH}$, Moretta A, Caligiuri MA, Zitvogel L, Lanier LL, et al, Innate or adaptive immunity? The example of natural killer cells. Science. 2011;331:44-9.

11. O'Sullivan TE, Sun JC, Lanier LL. Natural killer cell memory. Immunity. 2015; 43:634-45

12. Mariani $E$, Meneghetti A, Neri S, Ravaglia G, Forti P, Cattini $L$, et al. Chemokine production by natural killer cells from nonagenarians. Eur J Immunol. 2002;32:1524-9.

13. Fauriat $\mathrm{C}$, Long EO, Ljunggren $\mathrm{H}-\mathrm{G}$, Bryceson $\mathrm{YT}$. Regulation of human NK-cell cytokine and chemokine production by target cell recognition Blood. 2010;115:2167-76

14. De Maria A, Bozzano F, Cantoni C, Moretta L. Revisiting human natural killer cell subset function revealed cytolytic CD56dimCD16+ NK cells as rapid producers of abundant IFN- $\gamma$ on activation. Proc Natl Acad Sci. 2011;108: 728-32.

15. Liao W, Lin J-X, Leonard WJ. Interleukin-2 at the crossroads of effector responses, tolerance, and immunotherapy. Immunity. 2013;38:13-25.
16. Gotthardt D, SexI V. STATs in NK-cells: the good, the bad, and the ugly. Front Immunol. 2017:7:694.

17. Dhupkar P, Gordon N. Interleukin-2: old and new approaches to enhance immune-therapeutic efficacy. Adv Exp Med Biol. 2017:995:33-51.

18. Yu TK, Caudell EG, Smid C, Grimm EA. IL-2 activation of NK cells: involvement of MKK1/2/ERK but not p38 kinase pathway. J Immunol. 2000;164:6244-51.

19. Goodier MR, Londei M. Lipopolysaccharide stimulates the proliferation of human CD56+CD3- NK cells: a regulatory role of monocytes and IL-10. J Immunol. 2000;165:139-47.

20. Varma TK, Lin CY, Toliver-Kinsky TE, Sherwood ER. Endotoxin-induced gamma interferon production: contributing cell types and key regulatory factors. Clin Diagn Lab Immunol. 2002;9:530-43.

21. Mian MF, Lauzon NM, Andrews DW, Lichty BD, Ashkar AA. FimH can directly activate human and murine natural killer cells via TLR4. Mol Ther. 2010;18:1379-88.

22. O'Connor GM, Hart OM, Gardiner CM. Putting the natural killer cell in its place. Immunology. 2006;117:1-10.

23. Souza-Fonseca-Guimaraes F, Parlato M, Philippart F, Misset B, Cavaillon J-M, Adib-Conquy $M$, et al. Toll-like receptors expression and interferon- $\gamma$ production by NK cells in human sepsis. Crit Care. 2012;16:R206.

24. Tamai R, Asai Y, Hashimoto M, Fukase K, Kusumoto S, Ishida H, et al. Cell activation by monosaccharide lipid $\mathrm{A}$ analogues utilizing Toll-like receptor 4. Immunology. 2003;110:66-72.

25. Bonizzi G, Karin M. The two NF-kB activation pathways and their role in innate and adaptive immunity. Trends Immunol. 2004;25:280-8.

26. Kanevskiy LM, Telford WG, Sapozhnikov AM, Kovalenko El. Lipopolysaccharide induces IFN- $\gamma$ production in human NK cells. Front Immunol. 2013:4:1-10.

27. Chopra RK, Nagel JE, Chrest FJ, Immunology WHAC. Impaired phorbol ester and calcium ionophore induced proliferation of T cells from old humans; 1987. p. 456-62.

28. Kaszubowska L, Dettlaff-Pokora A, Hak L, Szarynska M, Ryba M, Mysliwska J, et al. Successful ageing of nonagenarians is related to the sensitivity of NK cells to activation. J Physiol Pharmacol. 2008;59(Suppl.9):187-99.

29. Elpek KG, Rubinstein MP, Bellemare-Pelletier A, Goldrath AW, Turley SJ. Mature natural killer cells with phenotypic and functional alterations accumulate upon sustained stimulation with IL-15/IL-15Ralpha complexes. Proc Natl Acad Sci U S A. 2010;107:21647-52.

30. Chang G-W, Hsiao C-C, Peng Y-M, Vieira Braga FA, Kragten NAM, Remmerswaal EBM, et al. The adhesion G protein-coupled receptor GPR56/ADGRG1 is an inhibitory receptor on human NK cells. Cell Rep. 2016;15:1757-70.

31. Liu Z, Kharmate G, Patterson E, Khan MM. Role of H1 receptors in histaminemediated up-regulation of STAT4 phosphorylation. Int Immunopharmacol. 2006;6:485-93.

32. Wendt K, Wilk E, Buyny S, Buer J, Schmidt RE, Jacobs R. Gene and protein characteristics reflect functional diversity of CD56dim and CD56bright NK cells. J Leukoc Biol. 2006;80:1529-41.

33. Bueno V, Sant'Anna OA, Lord JM. Ageing and myeloid-derived suppressor cells: possible involvement in immunosenescence and age-related disease. Age. 2014;36:9729.

34. Franceschi C, Bonafe M, Valensin S, Olivieri F, De Luca M, Ottaviani E, et al. Inflamm-aging. An evolutionary perspective on immunosenescence. Ann N Y Acad Sci. 2000;908:244-54

35. Barja G. Free radicals and aging. Trends Neurosci. 2004:27:595-600.

36. de Toda IM, De la Fuente M. The role of Hsp70 in oxi-inflamm-aging and its use as a potential biomarker of lifespan. Biogerontology. 2015;16:709-21.

37. Bauer ME, De La Fuente M. The role of oxidative and inflammatory stress and persistent viral infections in immunosenescence. Mech Ageing Dev. 2016;158:27-37.

38. Calabrese V, Boyd-Kimball D, Scapagnini G, Butterfield DA. Nitric oxide and cellular stress response in brain aging and neurodegenerative disorders: the role of vitagenes. In Vivo. 2004;18:245-67.

39. Salway KD, Gallagher EJ, Page MM, Stuart JA. Higher levels of heat shock proteins in longer-lived mammals and birds. Mech Ageing Dev. 2011;132:287-97.

40. Merksamer PI, Liu Y, He W, Hirschey MD, Chen D, Verdin E. The sirtuins, oxidative stress and aging: an emerging link. Aging (Albany NY). 2013;5:144-50.

41. Brunet A, Sweeney LB, Sturgill JF, Chua KF, Greer PL, Lin Y, et al. Stressdependent regulation of FOXO transcription factors by the SIRT1 deacetylase. Science. 2004:303:2011-5.

42. van der Horst A, Tertoolen LG, de Vries-Smits LM, Frye RA, Medema RH, Burgering BM. FOXO4 is acetylated upon peroxide stress and deacetylated by the longevity protein hSir2(SIRT1). J Biol Chem. 2004;279:28873-9. 
43. Rodgers JT, Lerin C, Haas W, Gygi SP, Spiegelman BM, Puigserver P. Nutrient control of glucose homeostasis through a complex of PGC-1a and SIRT1. Nature. 2005;434:113-8.

44. St-Pierre J, Drori S, Uldry M, Silvaggi JM, Rhee J, Jäger S, et al. Suppression of reactive oxygen species and neurodegeneration by the PGC-1 transcriptional coactivators. Cell. 2006;127:397-408.

45. Westerheide SD, Anckar J, Jr SMS, Sistonen L, Morimoto RI. Stress-inducible regulation of heat shock factor 1 by thr deacetylase SIRT1. Science. 2009; 323:1063-6.

46. Saunders LR, Verdin E. Stress response and aging. Science. 2009;323:1021-2.

47. Kaszubowska L, Foerster J, Kaczor JJ, Schetz D, Ślebioda TJ, Kmieć Z. NK cells of the oldest seniors represent constant and resistant to stimulation high expression of cellular protective proteins SIRT1 and HSP70. Immun Ageing. 2018;15:12.

48. Folstein MF, Folstein SE, McHugh PR. "Mini-mental state". A practical method for grading the cognitive state of patients for the clinician. J Psychiatr Res. 1975;12:189-98.

49. Katz S, Ford AB, Moskowitz RW, Jackson BA, Jaffe MW. Studies of illness in the aged. The index of Adl: a standardized measure of biological and psychosocial function. JAMA. 1963;185:914-9.

50. Poli A, Michel T, Theresine M, Andres E, Hentges F, Zimmer J. CD56bright natural killer (NK) cells: an important NK cell subset. Immunology. 2009;126: 458-65.

51. Calabrese V, Cornelius C, Dinkova-Kostova AT, lavicoli I, Di Paola R, Koverech A, et al. Cellular stress responses, hormetic phytochemicals and vitagenes in aging and longevity. Biochim Biophys Acta - Mol Basis Dis. 2012;1822:753-83.

52. Kovalenko El, Boyko AA, Semenkov VF, Lutsenko GV, Grechikhina MV, Kanevskiy LM, et al. ROS production, intracellular HSP70 levels and their relationship in human neutrophils: effects of age. Oncotarget. 2014:5:1 1800-12.

53. Singh T, Newman A. Inflammatory markers in population studies of ageing. Ageing. 2011;10:2-22.

54. Njemini R, Bautmans I, Lambert M, Demanet C, Mets T. Heat shock proteins and chemokine/cytokine secretion profile in ageing and inflammation. Mech Ageing Dev. 2007;128:450-4.

55. Owczarz M, Budzinska M, Domaszewska-Szostek A, Borkowska J, Polosak J, Gewartowska M, et al. miR-34a and miR-9 are overexpressed and SIRT genes are downregulated in peripheral blood mononuclear cells of aging humans. Exp Biol Med (Maywood). 2017;242:1453-61.

56. Zou X, Ratti BA, Gerald O 'brien J, Lautenschlager SO, Gius DR, Bonini MG, et al. Manganese superoxide dismutase (SOD2): is there a center in the universe of mitochondrial redox signaling? J Bioenerg Biomembr. 2017;49:325-33.

57. Pansarasa O, Bertorelli L, Vecchiet J, Felzani G, Marzatico F. Age-dependent changes of antioxidant activities and markers of free radical damage in human skeletal muscle. Free Radic Biol Med. 1999:27:617-22.

58. Schanzle JC, Deo SH, Fadel PJ. Systemic oxidative stress in older adults: do peripheral blood mononuclear cells contribute? FASEB J. 2013;27(Suppl 1):1142.6

59. De Maio A. Extracellular heat shock proteins, cellular export vesicles, and the stress observation system: a form of communication during injury, infection, and cell damage. It is never known how far a controversial finding will go! Dedicated to Ferruccio Ritossa. Cell Stress Chaperones. 2011;16:235-49.

60. Armijo G, Okerblom J, Cauvi DM, Lopez V, Schlamadinger DE, Kim J, et al. Interaction of heat shock protein 70 with membranes depends on the lipid environment. Cell Stress Chaperones. 2014;19:877-86.

61. Multhoff $G$, Hightower LE. Distinguishing integral and receptor-bound heat shock protein 70 (Hsp70) on the cell surface by Hsp70-specific antibodies. Cell Stress Chaperones. 2011;16:251-5.

62. Young JC, Hoogenraad NJ, Hartl FU. Molecular chaperones Hsp90 and Hsp70 deliver Preproteins to the mitochondrial import receptor Tom70. Cell. 2003;112:41-50.

63. Afolayan AJ, Teng R-J, Eis A, Rana U, Broniowska KA, Corbett JA, et al. Inducible HSP70 regulates superoxide dismutase-2 and mitochondrial oxidative stress in the endothelial cells from developing lungs. AJP Lung Cell Mol Physiol. 2014;306:L351-60.

64. Afolayan AJ, Alexander M, Holme RL, Michalkiewicz T, Rana U, Teng R-J, et al. Domain mapping of heat shock protein 70 reveals that glutamic acid 446 and arginine 447 are critical for regulating superoxide dismutase 2 function. J Biol Chem. 2017;292:2369-78.

65. Asea A, Kraeft S-K, Kurt-Jones EA, Stevenson MA, Chen LB, Finberg RW, et al. HSP70 stimulates cytokine production through a CD14-dependant pathway, demonstrating its dual role as a chaperone and cytokine. Nat Med. 2000;6: 435-42.
66. Asea A, Rehli M, Kabingu E, Boch JA, Bare O, Auron PE, et al. Novel signal transduction pathway utilized by extracellular HSP70: role of toll-like receptor (TLR) 2 and TLR4. J Biol Chem. 2002;277:15028-34.

67. Detanico T, Rodrigues L, Sabritto AC, Keisermann M, Bauer ME, Zwickey H, et al. Mycobacterial heat shock protein 70 induces interleukin-10 production: immunomodulation of synovial cell cytokine profile and dendritic cell maturation. Clin Exp Immunol. 2004;135:336-42.

68. Luo X, Zuo X, Zhou Y, Zhang B, Shi Y, Liu M, et al. Extracellular heat shock protein 70 inhibits tumour necrosis factor-a induced proinflammatory mediator production in fibroblast-like synoviocytes. Arthritis Res Ther. 2008;10:R41.

69. Borges TJ, Wieten L, van Herwijnen MJC, Broere F, van der Zee R, Bonorino C, et al. The anti-inflammatory mechanisms of Hsp70. Front Immunol. 2012;3:95.

70. Ogawa K, Sanada K, Machida S, Okutsu M, Suzuki K. Resistance exercise training-induced muscle hypertrophy was associated with reduction of inflammatory markers in elderly women. Mediat Inflamm. 2010;2010:171023.

71. Caligiuri MA. Human natural killer cells. Blood. 2008;112:461-9.

72. Fehniger TA, Shah MH, Turner MJ, VanDeusen JB, Whitman SP, Cooper MA, et al. Differential cytokine and chemokine gene expression by human NK cells following activation with IL-18 or IL-15 in combination with IL-12: implications for the innate immune response. J Immunol. 1999;162:4511-20.

73. Solana R, Campos C, Pera A, Tarazona R. Shaping of NK cell subsets by aging. Curr Opin Immunol. 2014;29:56-61.

74. Li H, Lin X. Positive and negative signaling components involved in TNFalpha-induced NF-kappaB activation. Cytokine. 2008:41:1-8.

75. Dong J, Jimi E, Zeiss C, Hayden MS, Ghosh S. Constitutively active NFkappaB triggers systemic TNFalpha-dependent inflammation and localized TNFalpha-independent inflammatory disease. Genes Dev. 2010;24:1709-17.

76. Yang S-R, Wright J, Bauter M, Seweryniak K, Kode A, Rahman I, et al. Sirtuin regulates cigarette smoke-induced proinflammatory mediator release via RelA/p65 NF-kappaB in macrophages in vitro and in rat lungs in vivo: implications for chronic inflammation and aging. Am J Physiol Lung Cel Mol Physiol. 2007;292:567-76.

77. Pfluger PT, Herranz D, Velasco-Miguel S, Serrano M, Tschö MH. Sirt1 protects against high-fat diet-induced metabolic damage. Proc Natl Acad USA. 2008; 105:9793-8.

78. Sica A, Dorman L, Viggiano V, Cippitellit M, Ghosh P, Rice N, et al. Interaction of NF-kappaB and NFAT with the interferon-gamma promoter. Biol Chem. 1997;272:30412-20

79. Tassi I, Cella M, Presti R, Colucci A, Gilfillan S, Littman DR, et al. NK cellactivating receptors require PKC-theta for sustained signaling, transcriptional activation, and IFN-gamma secretion. Blood. 2008;112:4109-16.

80. Thomsen MK, Bakiri L, Hasenfuss SC, Hamacher R, Martinez L, Wagner EF. JUNB/AP-1 controls IFN- $y$ during inflammatory liver disease. J Clin Invest. 2013:123:5258-68.

81. Kang H-B, Ahn K-S, Oh S-R, Kim JW. Genkwadaphnin induces IFN- $\gamma$ via PKD1/NF-KB/STAT1 dependent pathway in NK-92 cells. PLoS One. 2014;9: e115146 Wang QJ, editor.

82. Oh S, Oh HW, Lee H-R, Yoon SY, Oh S-R, Ko Y-E, et al. Ingenane-type diterpene compounds from Euphorbia kansui modulate IFN- $\gamma$ production through NF-KB activation. J Sci Food Agric. 2016;96:2635-40.

83. Krause M, Keane K, Rodrigues-Krause J, Crognale D, Egan B, De Vito G, et al. Elevated levels of extracellular heat-shock protein 72 (eHSP72) are positively correlated with insulin resistance in vivo and cause pancreatic $\beta$-cell dysfunction and death in vitro. Clin Sci. 2014;126:739-52.

84. Qiao Y, Liu B, Li Z. Activation of NK cells by extracellular heat shock protein 70 through induction of NKG2D ligands on dendritic cells. Cancer Immun. 2008:8:12

85. Kilic U, Gok O, Erenberk U, Dundaroz MR, Torun E, Kucukardali Y, et al. A remarkable age-related increase in SIRT1 protein expression against oxidative stress in elderly: SIRT1 gene variants and longevity in human. PLoS One. 2015;10:e0117954.

86. Kaszubowska L, Kaczor JJ, Hak L, Dettlaff-Pokora A, Szarynska M, Kmiec Z. Sensitivity of natural killer cells to activation in the process of ageing is related to the oxidative and inflammatory status of the elderly. J Physiol Pharmacol. 2011;62:101-9.

87. Valiathan R, Ashman M, Asthana D. Effects of ageing on the immune system: infants to elderly. Scand J Immunol. 2016;83:255-66. 